Florida International University

FIU Digital Commons

$1-27-2019$

\title{
A Comparison Study of the Executive Functioning Abilities and Reading Comprehension Skills of Students in Response to Intervention
}

Catherine Schultheis Salum

Florida International University, cschu003@fiu.edu

Follow this and additional works at: https://digitalcommons.fiu.edu/etd

Part of the Cognitive Psychology Commons, Educational Psychology Commons, Language and Literacy Education Commons, School Psychology Commons, and the Special Education and Teaching Commons

\section{Recommended Citation}

Salum, Catherine Schultheis, "A Comparison Study of the Executive Functioning Abilities and Reading Comprehension Skills of Students in Response to Intervention" (2019). FIU Electronic Theses and Dissertations. 3953.

https://digitalcommons.fiu.edu/etd/3953

This work is brought to you for free and open access by the University Graduate School at FIU Digital Commons. It has been accepted for inclusion in FIU Electronic Theses and Dissertations by an authorized administrator of FIU Digital Commons. For more information, please contact dcc@fiu.edu. 


\title{
FLORIDA INTERNATIONAL UNIVERSITY
}

Miami, Florida

\section{A COMPARISON STUDY OF THE EXECUTIVE FUNCTIONING ABILITIES AND READING COMPREHENSION SKILLS OF STUDENTS IN RESPONSE TO INTERVENTION}

\author{
A dissertation submitted in partial fulfillment of the \\ requirements for the degree of \\ DOCTOR OF EDUCATION \\ in \\ EXCEPTIONAL STUDENT EDUCATION
}

by

Catherine S. Salum

2019 
To: Dean Michael R. Heithaus

College of Arts, Sciences, and Education

This dissertation, written by Catherine S. Salum, and entitled, A Comparison Study of the Executive Functioning Abilities and Reading Comprehension Skills of Students in

Response to Intervention having been approved in respect to style and intellectual content, is referred to you for judgment.

We have read this dissertation and recommend that it be approved.

$\begin{array}{r}\text { Liana Gonzalez } \\ \hline \text { Thomas Reio } \\ \hline \text { Elizabeth Cramer, Major Professor }\end{array}$

Date of Defense: January 29, 2019

The dissertation of Catherine S. Salum is approved.

Dean Michael R. Heithaus

College of Arts, Sciences, and Education

Andres G. Gil

Vice President for Research and Economic Development and Dean of the University Graduate School

Florida International University, 2019 
C Copyright 2019 by Catherine Salum

All rights reserved. 


\section{ACKNOWLEDGMENTS}

I would like to thank the members of my committee for their dedication, time, and assistance in completing this dissertation. I would especially like to thank my major professor, Elizabeth Cramer, without whom this study would not have been possible. Your guidance, patience, and expertise made this dissertation and my doctoral experience immensely rewarding. Also, I would like to thank the administrators and teachers from Miami Dade county public schools, particularly Sweetwater Elementary, Frances Tucker Elementary, and Pinecrest Elementary for supporting me and allowing me to run this study in their schools. Lastly, I would like to thank my husband, children, and parents for their countless love and support. 


\begin{abstract}
OF THE DISSERTATION
A COMPARISON STUDY OF THE EXECUTIVE FUNCTIONING ABILITIES AND

READING COMPREHENSION SKILLS OF STUDENTS IN RESPONSE TO

INTERVENTION
\end{abstract}

by

Catherine S. Salum

Florida International University, 2019

Miami, Florida

Professor Elizabeth Cramer, Major Professor

Response to intervention (RTI) is a data driven framework that classifies students into three tiers and provides interventions at different levels of intensity (Flanagan, Ortiz, Alfonso, \& Dynada, 2006; Fuchs, Fuchs, \& Stecker, 2010, Gilbert et al., 2012). The screening assessments and interventions used for RTI have become generalized (Garcia, Gonzalez-Castro, Fernandez, \& Rodriguez-Perez, 2012). Many schools implementing RTI use one screening instrument and one intervention for all struggling readers (Ezpeleta, Granero, Penelo, de la Osa, \& Domenech, 2015; Flanagan et al., 2006; Garcia et al., 2012; Gilbert et al., 2012).

Executive functioning $(\mathrm{EF})$ is a neuropsychological ability that regulates behaviors and cognitions to guide behaviors to accomplish a goal (Bledsoe, SemrudClikeman, \& Pliszka, 2010; Coghill, Seth, \& Matthews, 2014; Ezpleta et al., 2015; Goldstein et al., 2014; Zelazo, 2016). Inhibition, cognitive flexibility, and working 
memory are three core processes of EF that affect reading comprehension (Cartwright, 2016; Dahlin, 2011; Miyake et al., 2000). EF assessments and screeners provide valuable information for designing interventions, as most Tier 2 and Tier 3 RTI reading interventions focus primarily on the linguistic nature of tasks without taking into consideration other relevant domains like EF (Garcia-Fernandez et al., 2012; Goldstein et al., 2014).

For this study, the researcher collected data on the reading comprehension, language, and EF abilities for 87 elementary school students ages seven through ten. The data were categorized into RTI Tier 1, Tier 2, or Tier 3 depending on their reading comprehension results. Correlations, MANOVAS, and regressions were conducted to analyze the data and study the hypothesis that explored relationships and predictive abilities of EF on reading comprehension.

The results demonstrated correlations between the EF abilities and reading comprehension skills. Working memory demonstrated significant predictive capabilities for reading comprehension deficits (RCD). Language abilities demonstrated the strongest predictive ability for RCD. These results have implications for the literature on RTI diagnostic testing/screenings, RTI intervention development, and the implications of EF on RCD. These results support the use of EF rating scales as screening assessments for practitioners to implement when making decisions on RTI. 


\section{TABLE OF CONTENTS}

CHAPTER

PAGE

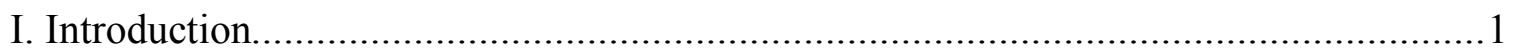

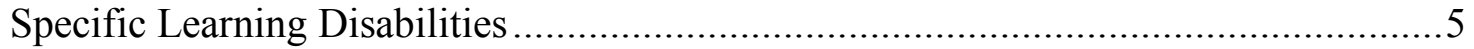

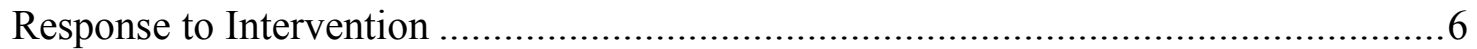

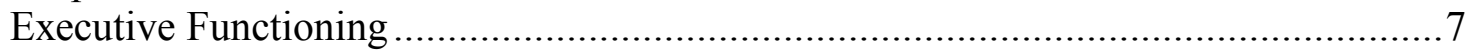

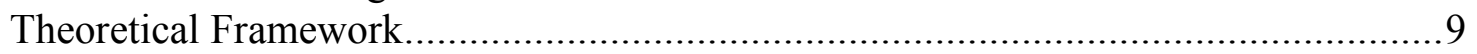

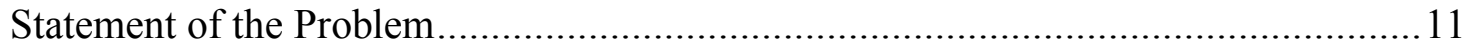

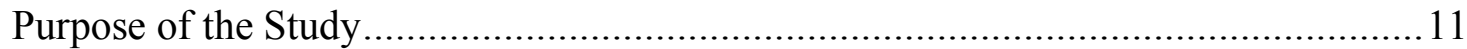

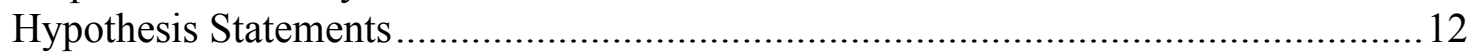

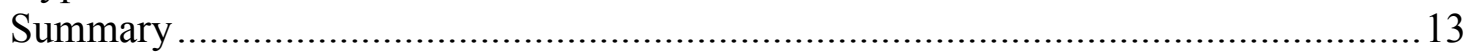

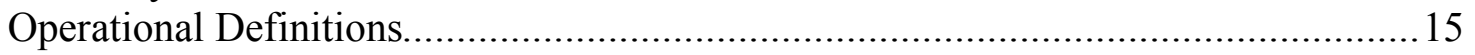

II. Literature Review .......................................................... 17

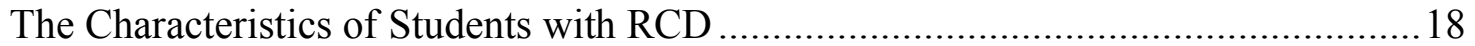

Theoretical Framework: Executive Functioning .....................................................25

Clinical Manifestations of EF Disorders and How they relate to RCD.........................30

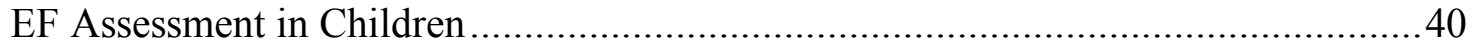

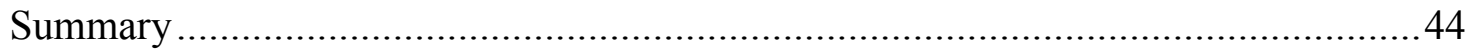

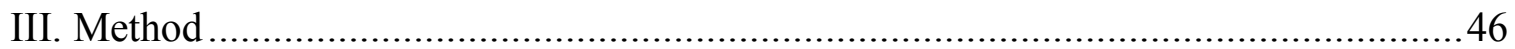

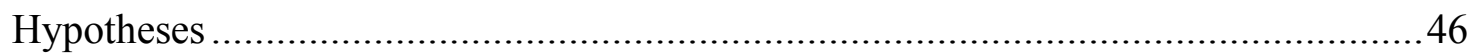

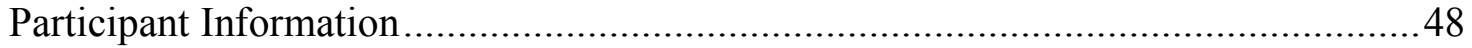

Data Collection Instruments...........................................................................5

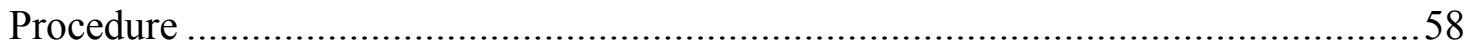

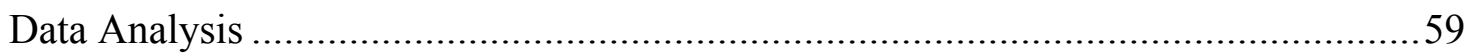

Summary

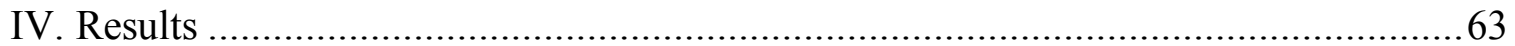

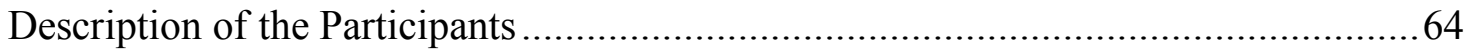

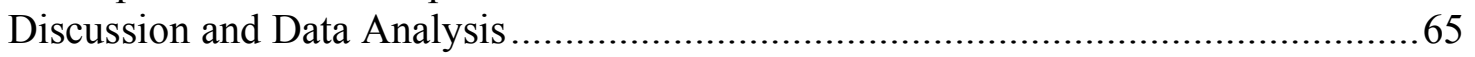

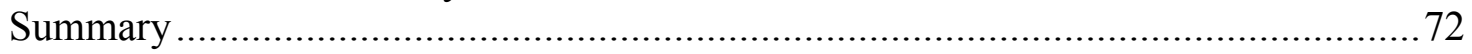

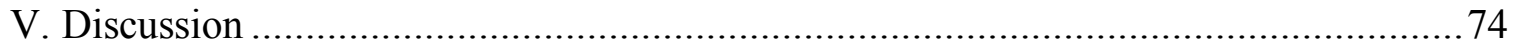

Findings Related to the First Hypothesis Statement................................................ 74

Findings Related to the Second Hypothesis Statement .............................................76

Findings Related to the Third Hypothesis Statement .................................................78

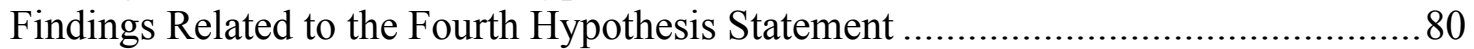

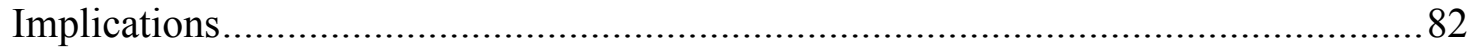

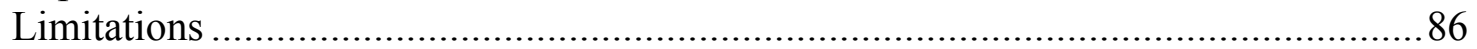

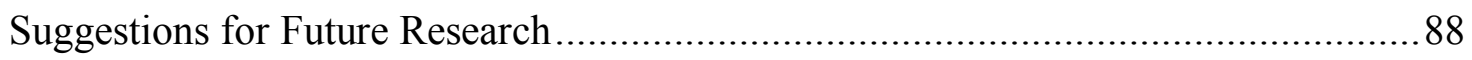




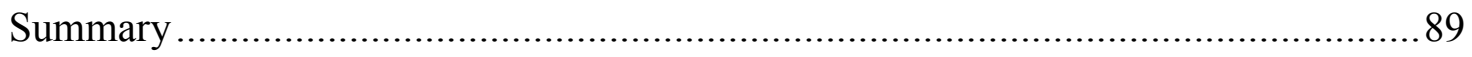

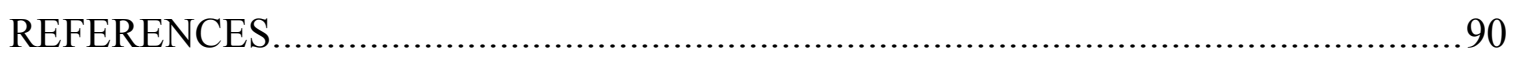

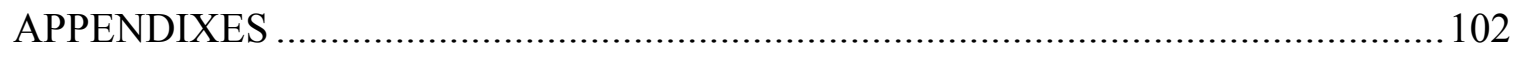

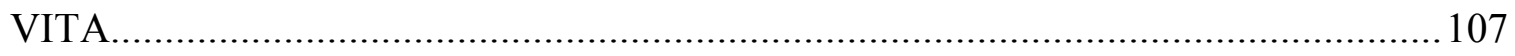




\section{LIST OF TABLES}

TABLE

PAGE

1. RTI tiers -2017-2018 iReady Scale Score Placement Tables ....................50

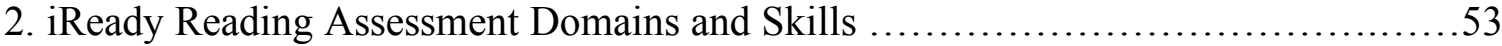

3. Correlations by EF Abilities..............................................65

4. BRIEF-2 Means and Standard Deviations by RTI Tier.........................66

5. BRIEF-2 Correlations with Reading Comprehension..........................69

6. Multiple Regression Analysis of EF Scores and RC Scores....................... 70

7. Hierarchical Regression Analysis..........................................72 


\section{CHAPTER I}

\section{Introduction}

For years, children with disabilities were denied the same opportunity for education as their non-disabled peers (National Center for Learning Disabilities [NCLD], 2017). It was not until 1975, when congress enacted the Education for all Handicapped Children Act (EHA), later termed the Individuals with Disabilities Education Act (IDEA) in 1990, that students with disabilities were offered the opportunity to receive a free and appropriate education through special education programs (NCLD, 2017). Special Education (SPED) programs were divided into 13 different classifications depending on the child's needs. One of the special education disability classifications under IDEA is specific learning disabilities (SLD), a disability that affects learning in reading, writing, and/or math. Specific learning disability quickly became the most rapidly growing special education category increasing by almost 300\% between 1976 and 2000 (Kavale \& Spaulding, 2008; NCLD, 2017).

In 1977, the Department of Education made the presence of a discrepancy between academic functioning and IQ the primary criterion for SLD identification. This criterion was problematic because it failed to align the student's identification of SLD with instruction. Researchers and educators found the number of children being diagnosed to be inflated and suspected that school staffs were overclassifying and/or failing students at some level (Gilbert, Compton, Fuchs, \& Fuchs, 2012; Kavale \& Spaulding, 2008). The SLD identification criteria has created an over identification of students with SLD because of poor instruction (Gilbert et al., 2012). Thus, IDEA part B was published in 2006, which provided a revision of the plan's requirements for 
education and classification. Subsequently, the number of students classified with SLD declined at a rate of approximately $2 \%$ per year, leading to an $18 \%$ decline between 2002 and 2011 (NCLD, 2017). Researchers attribute this rapid decline to several factors, including the changes in the identification methods for SLD (NCLD, 2017). While the changes varied by state, most adopted the response to intervention (RTI) method, which provides early scientific research-based interventions in the general education setting to struggling students (Gilbert et al., 2012; Kavale \& Spaulding, 2008).

Response to intervention has three core concepts: the application of scientifically based research interventions, the measurement of response and learning rate, and the use of data to make instructional decisions (Kavale \& Spaulding, 2008). Response to intervention provides students with three tiers of instruction: Tier 1 provides general education instruction with simple interventions, and tiers two and three provide intensified instruction (Kavale \& Spaulding, 2008). Interventions for tiers two and three include, decreasing the teacher to student ratio, increasing the intensity, and increasing the time of the added interventions (Kavale \& Spaulding, 2008). The implementation of RTI has resulted in a decline in the number of student referrals for special education, an increase in the number of students receiving interventions within the general education setting, and an increase in the number of SPED students receiving most of their education in the inclusion setting. As of 2017 , about $70.9 \%$ of students with SLD are spending $80 \%$ of their school day in the general education setting, up from $47 \%$ a decade ago (NCLD, 2017).

Much of the research confirms that students in special education programs who experience most of their academic instruction in general education have better academic 
outcomes, indicating that the changes that have come about from IDEA Part B and RTI are mostly positive (Bledsoe, Semrud-Clikeman, \& Pliszka, 2010; Gilbert et al., 2012; Kavale \& Spaulding, 2008; NCLD, 2017; O’Connor, Bocian, Beach, Sanchez, \& Flynn, 2013). However, data indicate that $15 \%$ or more of students in RTI Tier 2 or Tier 3 are reported as continuing to struggle because of unidentified and unaddressed learning issues (Flanagan, Ortiz, Alfonso, \& Dynda, 2006; Fuchs, Fuchs, \& Stecker, 2010; Garcia, Gonzalez-Castro, Fernandez, \& Rodriguez-Perez, 2012; Gilbert et al., 2012; Kavale \& Spaulding, 2008; NCLB, 2014; O’Connor et al., 2013). Thus, many researchers have expressed concerns about the intervention system falling short (Kavale \& Spaulding, 2008; Fuchs, Fuchs, \& Stecker, 2010; Garcia et al., 2012; Gilbert et al., 2012; Flanagan, Ortiz, Alfonso, \& Dynda, 2006; NCLD, 2017; O'Connor et al., 2013).

While RTI has proven to be a good source of early intervention, the lack of individualized evaluations, planning, and instruction has led to the generalization of interventions (Kavale \& Spaulding, 2008). The interventions may not be addressing comorbid issues such as, processing deficits, executive functioning (EF) deficits, and attention deficit hyperactivity disorder (ADHD), which are important factors affecting students with SLD (Flanagan et al., 2006). Thus, many students receiving interventions using the RTI framework continue to struggle. "Although the use of scientifically research-based interventions is advantageous, RTI remains a one-size-fits-all approach focusing on treatment validity" (Kavale \& Spaulding, 2008, p.170). Additionally, students who do not respond to interventions at the tier two and tier three levels are being considered as having a learning delay or possible learning disability, but practitioners are not considering the other factors, particularly EF, that could be affecting their academic 
success (Bledsoe, Semrud-Clikeman, \& Pliszka, 2010). For example, children with SLD often experience academic underachievement and have difficulties with EF (Bledsoe et al., 2010).

Executive functioning refers to the abilities that allow students to self-regulate cognitive stores, inhibit responses that are irrelevant, and manipulate and organize multiple fragments of information concurrently (Bledsoe et al., 2010). Executive functioning abilities are the tools and aptitudes that students possess to learn the skills necessary to become successful academically (Bledsoe et al., 2010). Completing EF assessments or screeners during the early data collection phase of RTI could offer valuable insight to students' abilities and help school staff understand if there are other areas of weakness impeding the students' learning (Garcia-Fernandez et al., 2012; Goldstein, Naglieri, Princiotta, \& Otero, 2014). Executive functioning screenings could provide valuable information for the designing of interventions, as most Tier 2 and Tier 3 RTI reading interventions focus mostly on the linguistic nature of tasks without taking into consideration other relevant domains (Garcia-Fernandez et al., 2012; Goldstein et al., 2014). While the implementation of RTI has helped decrease the overrepresentation of students with SLD in special education by providing additional help and interventions to students without labeling them and placing them in special education. Many students continue to struggle, possibly due to the non-customized nature of the interventions. As a result, gathering information on EF could improve the individuality of RTI interventions (Ezpeleta, Granero, Penelo, de la Osa, \& Domenech 2015; Flanagan et al., 2006; GarciaFernandez et al., 2012; Halloran, 2011; Koutsoftas, Harmon, \& Gray, 2009; Lee, Ng, \& 
Ng, 2009; Marzocchi et al., 2008; Menezes, Dias, Trevisan, Carreiro, \& Seabra, 2015;

Sesma, Mahone, Levine, Eason, \& Cutting 2009).

\section{Specific Learning Disabilities}

Specific learning disability can be defined as a disability that disrupts the normal pattern of learning academic skills that is not the result of a lack of opportunity to learn or inadequate instruction (Willcutt, Petrill, Wu, Boada, DeFries, Olson, \& Pennington, 2013). Students with SLD demonstrate skills in a specific academic area that are often one to two standard deviations below their age mean (Fry, Landry, Swank, \& Smith, 2009; Sesma et al., 2009; Willcutt et al., 2013). A student with SLD can have deficits in the areas of reading, written expression, and/or mathematics (Willcutt et al., 2013). Of the students classified as having SLD, deficits in reading (dyslexia) have been the most prevalent (Fry et al., 2009; Sesma et al., 2009).

\section{Reading disability (RD) and reading comprehension disability (RCD). RD}

refers to a specific type of SLD that affects a student's ability to read that is not attributed to cognitive deficits (Garcia-Fernandez et al., 2012; Halloran, 2011; Kibby, Marks, Morgan \& Long, 2004). Students with RD may display difficulties with phonological processing, spelling, decoding, fluency, and comprehension (Garcia-Fernandez et al., 2012; Halloran, 2011; Kibby et al., 2004). Reading comprehension deficit (RCD) refers to students who struggle to understand and give meaning to words in text. In addition, students with RCD many times struggle to develop age appropriate vocabulary as well as access prior knowledge when reading text. 


\section{Response to Intervention}

Response to intervention is the framework used to evaluate students for placement in academic intervention programs and special education. Placement is accomplished through universal screenings, early intervention, frequent progress monitoring, and intensive instruction or interventions derived from researched results (Flanagan et al., 2006; Fuchs et al., 2010; Gilbert et al., 2012; Koutsoftas et al., 2009). The success of the RTI framework relies on the accuracy with which the screening procedures identify the areas of strength and weakness (Gilbert et al., 2012). Using academic screeners is important, however research shows that conducting supplemental EF screeners can provide valuable information on a student's learning style (Ezpeleta, Granero, Penelo, de la Osa, \& Domenech, 2015; Garcia-Fernandez et al., 2012; Halloran, 2011; Kibby et al., 2004; Koutsoftas et al., 2009; Lee et al., 2009; Marzocchi et al., 2008; Menezes et al., 2015; Sesma et al., 2009).

Most RTI models are divided into three tiers. Tier 1 consists of whole group instruction. Statistically about $80 \%$ of the students in a class should be in Tier 1 (Fuchs et al., 2010). Tier 2 is designed for students who are struggling to meet expectation and follow the general curriculum. In this tier, the students are provided with additional support three to five times a week to supplement the general education curriculum. Typically, no more than $15 \%$ of the students in a class are placed in Tier 2 (Fuchs et al., 2010). Tier 3 is the most intensive level of intervention. Typically, a maximum of 5\% of the students in a class require this level of intervention. A student is considered for Tier 3 interventions if they have had some interventions in Tier 2 and are failing to respond to 
the intervention (Fuchs et al., 2010). At this point a team of experts will come together to design highly intensive and specialized interventions for the student.

\section{Executive Functioning}

Executive functioning can be broken down into the ability to initiate, plan, shift thinking or attention, organize, inhibit inappropriate thoughts or behaviors, use working memory, and sustain and sequence a behavior efficiently (Bledsoe et al., 2010; Coghill, Seth, \& Matthews, 2014; Ezpeleta et al., 2015; Goldstein et al., 2014; Halloran, 2011). Executive functioning refers to self-regulatory behaviors necessary to select and sustain actions and guide behavior to accomplish goals and follow rules (Bledsoe et al., 2010; Coghill et al., 2014; Ezpeleta et al., 2015; Goldstein et al., 2014; Halloran, 2011). In addition, it involves developing and implementing actions that allow for task completion (Bledsoe et al., 2010; Coghill et al., 2014; Ezpeleta et al., 2015; Goldstein et al., 2014; Halloran, 2011).

Individuals with deficits in EF struggle with everyday life activities, including the ability to learn, function independently, problem solve and develop and maintain appropriate social relations (Chan, Shum, Toulopoulou, \& Chen, 2008; GoldStein et al, 2014). In addition, EF impacts all areas of learning, making it a significant topic for teachers, psychologists, and others involved in remediating and strengthening academic difficulties. For this reason, continued research in this area can help others better understand and improve the learning difficulties of students with EF deficits (Goldstein et al., 2014). 
Executive functioning in students with reading disability. Many students who have $\mathrm{RD}$ experience difficulties in reading despite having average intellectual abilities and adequate educational opportunities (Garcia-Fernandez et al., 2012; Halloran, 2011; Kibby et al., 2004). Much of the research shows that issues in phonological processing and fluency negatively affect reading comprehension (Garcia-Fernandez et al., 2012; Halloran, 2011; Kibby et al., 2004; Pham \& Hasson, 2014). However, there are other non-language neuropsychological abilities and skills affecting reading comprehension such as non-verbal reasoning, memory, and other EF abilities (Frye, Landry, Swank, \& Smith, 2009; Goldstein et al., 2014; Pham \& Hasson, 2014; Sesma et al., 2009). Researchers' findings show that interventions that focus on building EF abilities should be implemented, in addition to interventions that work on word decoding, reading fluency, and comprehension (Bledsoe et al., 2010; Garcia-Fernandez et al., 2012; Halloran, 2011; Sesma et al., 2009). Research shows that children with RCD are less efficient in the usage of reading strategies, have poor self-regulation, and have difficulty coordinating and integrating information to effectively process written material (GarciaFernandez et al., 2012; Halloran, 2011; Sesma et al., 2009).

Assessment of executive functioning. The assessment of EF includes behavior observations at home and/or at school (Chan et al., 2008; Chevignard, Mariller, Abada, Pradat-Diehl \& Laurent-Vannier, 2009; Gioia, Isquith, \& Guy, 2001). According to Chan et al., (2008) teacher and parent structured behavior rating scales are considered verified methods for assessing social, emotional, behavioral, and executive functioning. These tools are common practice for many psychologists when completing a psychoeducational evaluation battery of tests (Chevignard et al., 2009; Gioia et al., 2001). 
Rating scales such as the Behavior Regulation Inventory of Executive

Functioning, Second Edition (BRIEF-2) have become the preferred method for assessing EF because it is difficult to measure the impact of EF deficits in everyday life (Chevignard et al., 2009). While there are various performance-based EF instruments that psychologists can use in a clinical setting, the validity of the test can be negatively affected as a result of the controlled structured environment that the psychologist provides (Chan et al., 2008). For example, the highly structured nature of a clinical setting does not encourage novel problem-solving abilities, instruction is given one to one, and the psychologist may provide encouragement, plan, and initiate tasks for the student (Chevignard et al., 2009). Research has shown discrepancies between students' performance on traditional measures of EF and real-world EF functioning (Chan et al., 2008; Chevignard er al., 2009). The traditional instruments of EF assessment are not measuring real life behavior or deficits.

\section{Theoretical Framework}

Research on EF can be traced back to the work of Alexander Luria (1902 - 1977), a Russian developmental and neuropsychologist. Luria was a pioneer in the study of neuropsychology, as his model changed the way many clinicians conceptualize and assess human brain functioning (Goldstein et al., 2014). Luria's theory of brain functioning identifies three functional units (Chan et al., 2008; Goldstein et al., 2014). These units are viewed as the building blocks of intelligence. Each unit is in a specific part of the brain and is responsible for different mental activities (Chan et al., 2008; Goldstein et al., 2014). "Each form of conscious activity is always a complex functional system and takes place through the combined working of all three brain units, each 
making its own contribution" (Luria, 1973, p.99). The three units work together in a hierarchical way by sending and receiving impulses to regulate behaviors (Luria, 1973). The first unit includes the brain stem and regulates the arousal of the cortex. The second unit involves the occipital, parietal, and temporal lobes, and works to encode, process, and store information. The third unit is in the frontal lobe and is responsible for programing, regulating, and verifying human behavior (Luria, 1973).

Executive functioning is associated with the third unit in Luria's theory of brain functioning. These abilities are said to be housed in the pre-frontal cortex and include the ability to plan, organize information, self-monitor, modify, and problem solve (Chan et al., 2008; McCloskey \& Perkins, 2012; Miyake, Friedman, Emerson, Witzki, Howerter, \& Wager, 2000; Semrud-Clikeman, Pliszka, \& Liotti, 2008). Much of the research shows that EF deficits are prevalent in different learning disorders such as ADHD and SLD, Tourette syndrome, and autism spectrum disorder (ASD; Bledsoe et al., 2010; Goldstein et al., 2014; McCloskey \& Perkins, 2012). Thus, a study that looks at EF patterns of strengths and weaknesses can offer insight into designing academic interventions and curricula for struggling students.

There is an abundance of research that shows the presence of EF deficits in children with SLD and, more specifically, RCD. However, there is limited research that explores the patterns of EF deficits in children struggling with RCD who are receiving interventions through the three RTI tiers. The present study aimed at examining the different profiles of EF in children who are struggling with RCD and receiving instruction via the RTI framework. 


\section{Statement of the Problem}

Response to intervention plays an important role in looking at the school population; however, students with disabilities require a specific and carefully studied curriculum that provides an intensive focus on an individual's specific needs. (Flanagan et al., 2006; Mather \& Gregg, 2006). The current study compares the patterns of EF strengths and weaknesses in students receiving reading comprehension interventions via the three RTI tiers. The goal of the study was to assess which specific EF strengths and weaknesses (i.e., working memory, inhibition, and cognitive flexibility/shifting) are found in students at the Tier 2 reading level and at the Tier 3 reading level as well as investigate any predictive abilities resulting from the EF abilities on reading comprehension. Executive functioning screening data is critical for improving RTI diagnostic testing/screenings as well as designing more individualized interventions for struggling readers.

\section{Purpose of the Study}

This study has implications for the literature on RTI intervention development, RTI diagnostic testing/screenings, and the implications of executive functioning on reading disorders. Prevalence studies have demonstrated that EF plays an important role in reading comprehension. The study aims to contribute to the growing knowledge of the specific EF strengths and weaknesses that are affecting the reading comprehension skills of struggling students in elementary schools. Current research supports that there are benefits to including data on EF deficits to improve reading interventions.

It is important for teachers and parents to understand what EF abilities are and how they impact reading comprehension so that they can help students enhance these 
skills. Knowledge of students' EF abilities allow school intervention teams to develop treatment plans that are more individualized and target additional skills sets necessary for success through the RTI tiered interventions.

\section{Hypothesis Statements}

Executive functioning abilities are necessary for success in reading comprehension (Carlson et al., 2013; Garon et al., 2008; Hughes, 2011; Jacques \& Marcovitch, 2010; Meuwissen \& Zelazo, 2014). The present study attempted to explore the following hypothesis statements regarding the relationship between EF strengths and weaknesses and reading comprehension skills for a group of public elementary school students in RTI reading to improve the individualization of instructional reading comprehension interventions. The exploration occurred through the quantitative analysis of the students' reading comprehension achievement data, vocabulary scores and EF ability scores to determine correlations and regression analyses.

$\mathrm{H}_{01}$ : There is not a significant difference in EF, using the BRIEF-2 TRF inhibition, cognitive flexibility, and working memory scores, between the grade level readers (Tier 1), at risk readers (Tier 2) and poor readers (Tier 3), based on iReady reading assessment (reading comprehension).

$\mathrm{H}_{1}$ : There is a significant difference in EF abilities between grade level readers (Tier 1), at risk readers (Tier 2), and poor readers (Tier 3).

$\mathrm{H}_{02}$ : Inhibition, cognitive flexibility, and working memory are specific EF abilities that do not correlate with reading comprehension skills.

$\mathrm{H}_{2}$ : There is a significant correlation between EF, using the BRIEF-2 TRF inhibition, cognitive flexibility, and memory scores, and reading comprehension for grade 
level readers (Tier 1), at risk readers (Tier 2) and poor readers (Tier 3), based on iReady reading assessment (reading comprehension).

$\mathrm{H}_{03}$ : Inhibition, cognitive flexibility, and working memory are EF abilities that do not significantly predict reading comprehension.

$\mathrm{H}_{3}$ : Inhibition, cognitive flexibility, and working memory EF abilities significantly predict reading comprehension in average (Tier 1), at risk readers (Tier 2) and poor readers (Tier 3), based on iReady reading assessment (reading comprehension).

$\mathrm{H}_{04}$ : Inhibition, cognitive flexibility, and working memory are EF abilities that do not predict reading comprehension after controlling for language skills.

$\mathrm{H}_{4}$ : Inhibition, cognitive flexibility, and working memory EF abilities predict reading comprehension, after controlling for language, based on iReady reading assessment (vocabulary) in grade level (Tier 1), at risk readers (Tier 2) and poor readers (Tier 3).

\section{Summary}

The number of students receiving special education services under the SLD classification is disproportionately higher than for any other disabilities such as ASD, intellectual disability, emotional and behavioral disability, and ADHD (Cortiella \& Horowitz, 2014; Flanagan et al., 2006; Fuchs et al., 2010; Kavale \& Spaulding, 2008; Koutsoftas et al., 2009; Mather \& Gregg, 2006; \& NCLB, 2014). This raised concerns that led federal and state policymakers to introduce IDEA part B, a revised plan of the requirements for the education and classification of students in SPED with SLD (NCLB, 2014). Many states adopted the RTI framework for the identification and educational planning of struggling students. 
Response to intervention requires school staff to provide early scientific researchbased interventions in the general education setting to struggling students (Flanagan et al., 2006; Fuchs et al., 2010; Kavale \& Spaulding, 2008; NCLD, 2014). The RTI framework provides more students with early interventions and academic assistance, resulting in fewer student referrals for SLD (Flannagan et al., 2006; Fuchs et al., 2010; Kavale \& Spaulding, 2008; NCLD, 2014). One way is to further individualize the intervention process, particularly in students struggling in reading comprehension by screening for EF deficits.

Executive functioning refers to the self-regulatory abilities to initiate, plan, shift thinking or attention, organize, inhibit inappropriate thoughts or behaviors, problem solve, and memorize (Bledsoe et al., 2010; Coghill et al., 2014; Ezpeleta et al., 2015; Goldstein et al., 2014; Halloran, 2011). Learning of the students'strengths and weaknesses in EF allows teachers to target neuropsychological abilities and skills that affect reading comprehension such as memory, inhibition, attention, and cognitive flexibility/ shifting. Interventions that target EF deficits help to supplement traditional reading interventions that focus on phonological processing, fluency, and comprehension. There are various studies that showed positive correlations and positive outcomes between EF and SLD (Ezpeleta et al., 2015; Garcia-Fernandez et al., 2012; Halloran et al., 2011; Lee et al., 2009; Marzocchi et al., 2008; Menezes et al., 2015; SemrudClikeman et al., 2010; Sesma et al., 2009). These researchers found connections between EF abilities and success in reading comprehension, written expression, mathematical problem solving, attention, focus, and impulse control (Ezpeleta et al., 2015; GarciaFernandez et al., 2012; Halloran et al., 2011; Lee et al., 2009; Marzocchi et al., 2008; 
Menezes et al., 2015; Semrud-Clikeman et al., 2010; Sesma et al., 2009). This study examined the correlational and predictive relationship between cognitive flexibility, inhibition, and working memory EF abilities on reading comprehension skills. The results provide data that can support the use of EF assessment as a screening tool to further individualize the types of RTI interventions provided to students who are struggling with RCD.

\section{Operational Definitions}

Behavior rating inventory of executive functioning (BRIEF-2). The BRIEF-2 is a 63 -item rating inventory completed by parents or teachers. It enables professionals to assess the executive functioning of a broad range of children, ages five to 18 years. The BRIEF-2 items form eight theoretically and empirically derived clinical scales that measure different aspects of EF: Inhibit, Shift, Emotional Control, Initiate, Working Memory, Plan/Organize, Organization of Materials, and Monitor (Gioia et al., 2001).

Executive functioning (EF). Executive functioning is a set of complex intellectual processes primarily housed in the prefrontal cortex area of the brain, which drive self-regulatory behaviors (Goldstein et al, 2014; Luria, 1973; McCloskey \& Perkins, 2012). They are mental processes that allow for planning, organization, attention, memory, and shifting, problem solving (Goldstein et al, 2014; Luria, 1973; McCloskey \& Perkins, 2012).

Reading disability (RD). A reading disability affects a student's performance in reading acquisition and/or comprehension (APA, 2013; Denton, 2012; Gilbert et al., 2012; \& Kibby et al., 2004). A student with RD may perform below the average in one or 
more of the following areas of reading: phonics, phonemic awareness, fluency, and/or comprehension. While $\mathrm{RD}$ is no longer a separate disability under the DSM-V, it is still considered and written in the descriptive text of SLD (APA, 2013).

Response to intervention (RTI). Response to intervention (RTI) is a framework that incorporates a multi-tiered intervention system where students are provided scientifically researched and evidence based academic interventions at varying degrees (Denton, 2012). Most school districts implement a three-tier model where the intensity of the intervention increases as needed. Tier 1 interventions are considered whole group general education instruction. Tier 2 interventions are more intensive and provide students with additional time and resources to improve in their academic area of weakness. Tier 3 interventions are the most intensive and individualized. Students are provided with more individualized interventions that target their specific areas of weakness.

Specific learning disability (SLD). A specific learning disability (SLD) is a disability that impacts academic achievement (American Psychiatric Association [APA], 2013; Cortiella \& Horowitz, 2014 \& Mather \& Gregg, 2006). Students with a SLD typically show signs of performing below average in reading (dyslexia), math (dyscalculia), and/or written expression (dysgraphia) (APA, 2013). 


\section{CHAPTER II}

\section{Literature Review}

This chapter will review the literature related to this study. Topics to be reviewed include: (a) the characteristics of students in RTI-Reading and/or with SLD/ RD, (b) the theoretical framework for EF, (c) the clinical manifestations of EF disabilities and how they relate to RCD, (d) the benefits of EF interventions when helping students with RCD and (e) EF assessment in children.

Specific learning disabilities (SLD) in reading, or reading disabilities (RD) are among the most prevalent challenges facing public school students in the U.S. (National Center for Learning Disabilities [NCLD], 2014; U.S. Department of Education [USDOE], 2015). To address this issue, over $90 \%$ of US states have incorporated response to intervention (RTI), a three-tiered approach to differentiating instruction through interventions for struggling readers (NCLD, 2014; USDOE, 2015). However, students continue to struggle as a consequence of most RTI frameworks' basic screening procedures, the generalized nature of interventions (Cartwright, 2012; Jacob \& Parkinson, 2015; Kavale \& Spaulding, 2008; Zimmerman, 2008) and their lack of consideration of other factors that impact reading acquisition. Research shows that students with RCD lack various developmental abilities, such as cognitive flexibility, inhibition, and working memory - all important components of executive functioning (EF) - that affect their ability to read and comprehend text (Cartwright, 2012; Melekoglu, 2011; Zelazo, Blair, \& Willoughby, 2016).

While most RTI frameworks do not consider a student's EF abilities, interventions that focus on improving reading-related EF abilities have proven successful 
because of the trainable and malleable nature of EF. Thus, knowledge of a student's EF strengths and weaknesses can be an asset when designing reading interventions (Cartwright, 2016). In addition, there are simple EF screening tools available that can provide valuable insights into a student's EF abilities. These tools can be administered during the RTI process to individualize interventions effectively (Garcia, GonzalezCastro, Fernandez, \& Rodriguez-Perez, 2012; Gilbert, Compton, Fuchs, \& Stecker, 2010; Kavale \& Spaulding, 2008; O’Connor, Bocian, Beach, Sanchez, \& Flynn, 2013).

\section{The Characteristics of Students with RCD}

The Diagnostic and Statistical Manual for Mental Disorders, fifth edition (DSMV) defines SLD as a neurodevelopmental disorder that impedes the ability to learn and use academic skills in reading, writing, and/or math (American Psychiatric Association [APA], 2013; Cartwright, 2012; Fry, Lanfry, Swank, \& Smith, 2009; Sesma, Mahone, Levine, Eason, \& Cutting, 2009; Willcutt et al., 2013). Currently, SLDs in reading are amongst the most prevalent (Carwright, 2012; NCLD, 2014; Zelazo, 2016). Thus, 90\% of states have adopted RTI, a three-tiered framework that is used to assist students who are struggling and falling behind in reading (Flanagan et al., 2006; Fuchs et al., 2010; Gilbert et al., 2012; Koutsoftas, Harmon, \& Gray, 2009; NCLD, 2014; USDOE, 2015). Students at Tier 2 often have reading skills below their grade level (Fuchs, Fuchs, \& Stecker, 2010). Students at Tier 3 are also functioning below grade level, have received individualized interventions and some have individualized education plans (IEPs) due to a reading disability (Fuchs et al., 2010). The present study examined students with RCD, which was defined as students who scored one grade level or below their current grade on 
the iReady reading comprehension assessment who are in RTI reading Tier 2, Tier 3, and/or students with a SLD in reading.

Reading acquisition begins with the learning of letter, names and sounds. The knowledge of sounds allows student to begin their understanding of phonics and phonemic awareness which is an important part of the acquisition of decoding skills (Denton, 2012; Gilbert, Compton, Fuchs, \& Fuchs, 2012; Spencer et al., 2014). Once a student has started decoding, he or she begins working on reading fluency and comprehension, as well as building an age appropriate vocabulary base (Denton, 2012; Gilbert et al., 2012; Spencer et al., 2014).

Early intervention. Students with RCD and students in RTI tiers 2 and 3 often struggle in the primary elementary years of reading instruction with an understanding of letter names, letter sounds, phonemes, and blending (Denton, 2012; Gilbert et al., 2012; Spencer et al., 2014). Some students will develop appropriate pre-reading skills and then show signs of a disability around age 10-11, because they are unable to read fluently or comprehend text (Cartwright, 2012; Denton, 2012; Gilbert et al., 2012). Students who show reading delays at an older age are a concern, because many students who struggle with reading at a young age continue to fall behind their peers as they move up in grades and the curriculum content becomes more challenging (Cartwright, 2012; Denton, 2016; Gilbert et al., 2012; Spencer et al., 2014).

Reading comprehension problems affect many elementary school children in the U.S. (Cartwright et al., 2016). One-third of third and fourth grade students in the US struggle to comprehend text (i.e. make inferences or extract important information from text) and two thirds of fourth grade students cannot proficiently comprehend text (i.e., 
integrate information, draw conclusions, and evaluate texts (Cartwright et al., 2016; Institute of Educational Sciences, 2013). For this reason, early differentiated screenings and interventions that address specific areas of weakness, both academic and with EF, are imperative for the development of readers who can proficiently comprehend text.

O'Connor and colleagues conducted a four-year longitudinal study on a group of struggling readers in grades one through four (O'Connor et al., 2013). The purpose of the study was to compare the identification rates for students with learning disability, as well as student characteristics of a group of 381 non-RTI students to 377 students in RTI for reading (O'Connor et al., 2013). The results indicated that one-third of students were not identified until fourth grade. In addition, results indicated that the students who participated in RTI had greater reading impairments than their peers who did not receive RTI interventions (O’Connor et al., 2013).

More recently, a study by Al Otaiba and colleagues (2014), examined the importance of early intervention. The study analyzed a group of 522 first grade students in 34 classrooms. A randomized controlled experiment compared a typical RTI model to a dynamic RTI model. The typical RTI model included various generalized steps that delayed students from moving from Tier 1 to tiers 2 and 3 . The dynamic RTI provided individualized Tier 2 or Tier 3 interventions immediately following the student's initial screening results. The interventions were identical; the only difference was when the interventions began. The results indicated that the students in the dynamic RTI model demonstrated higher reading performance supporting the importance of early intervention (Al Otaiba, Kim, Wanzek, Petscher, \& Wagner, 2014). Both studies demonstrate the importance of early identification and intervention for struggling readers. Current 
longitudinal research has demonstrated that nearly half of students with late emerging RD have issues with comprehension, and many of these students undetected difficulties may have been present at an earlier age (Al Otaiba et al., 2014; Catts et al., 2012; Nation, Cocksey, Taylor, \& Bishop, 2010; O’Connor et al., 2013).

Both studies listed above support the importance of early identification and early implementation individualized interventions for struggling readers. In addition, both studies support the importance of individualized interventions that are delivered at the correct intensity as soon as RCD may be suspected.

Comprehensive screenings and individualized interventions. While RTI is providing aid to struggling readers, the generic nature of the interventions may be failing students. A study by Gilbert and colleagues (2012), explored the importance of early individualized screenings for students at risk of RD. The goal of the study was to improve the RTI screening process by helping school psychologists, school personnel, and others establish school specific screening measures to identify RD. Researchers created a fourstep screening system that provides a framework for improving accuracy in classifying children who are at risk for RD (Gilbert, Compton, Fuchs, \& Fuchs, 2012). Researchers referred to accurate identification for students at risk for $\mathrm{RD}$ as (true positives) and those who were not at risk as true negatives (Gilbert et al., 2012). The failure to identify students at risk for $\mathrm{RD}$ is defined as a false negative, which results in a failure to provide needed interventions. A false positive occurs if the screening tool incorrectly identifies a student as at risk for $\mathrm{RD}$ and provides them with unnecessary interventions. Consequently, Gilbert and colleagues emphasize that "a solid screening process is critical to establish an RTI methodology that is effective and efficient for students and schools" 
(Gilbert et a., 2012, p. 7). Gilbert et al. identified the importance of developing a screening process that included sensitivity and specificity in the identification of students with RD. Sensitivity was defined as the percentage of truly at-risk students who are identified as at risk (true positives; Gilbert et al., 2012). Specificity was defined as the percentage of true negatives that were identified (Gilbert et al., 2012). The recommendations for a four-step process include:

Step 1 - Using a Universal Screening instrument, such as letter identification, oral reading fluency, phoneme segmentation and word identification.

Step 2 - Level one and Progress Monitoring such as fluency in letter identification, word reading fluency, sentence or passage reading fluency. Step 2 helps eliminate false positives, however does not help with false negatives.

Step 3 - Level two and follow up testing, such as standardized nationally normed tests and state achievement tests. Step 3 helps to eliminate false negatives.

Step 4 - Level three and upgrading procedures for subsequent years. The purpose of step 4 is to increase classification accuracy.

Per Gilbert and colleagues, the cut off scores for determining which students are at risk for RD vary depending on the unique characteristics of the school and/or school district. They provide a formula that calculates specificity and sensitivity to increase classification accuracy. Gilbert and colleagues' research supports that "a one-measure, one-time screening is not sufficient or adequate for identifying children who will or will not develop RD” (Gilbert et al., 2012, p. 10). In addition, Gilbert and colleagues delineate and provide important information that supports the importance of a thorough screening 
process that is also flexible to account for differences between schools and districts such as, academic levels, early education, parental support, and resources.

More recently, a study by Spencer and colleagues (2014) investigated the importance of an individualized screening process for identifying and helping students with RCD. The participants included 24,687 first grade students from "Reading First" schools in Florida. The students came from 291 elementary schools across 34 school districts (Spencer et al., 2014). Students were assessed using DIBELS in the four reading areas of decoding, sight word reading, reading comprehension, and listening comprehension, also a review of their RTI progress was conducted (Spencer et al., 2014). Researchers followed the students over a one-year period hoping to determine if a hybrid model that individualizes reading assessment is more effective than a single criterion using an operational definition to identify struggling readers. The results indicate the importance of using various measures and a hybrid model for identification of struggling readers, as students who are identified using a single criterion have limited stability over time (Spencer et al., 2014). Spencer and colleagues found that complex hybrid reading screenings study various aspects of reading and have longitudinal stability. Complex hybrid reading screenings study all aspects of reading that can help students, specifically, in third and fourth grade when the reading curriculum shifts from learning to read, to reading to learn different content areas such as history, literature, and science. In many situations, students with a RCD can have a reading level that falls three to five grade levels below their nondisabled peers (Cartwright, 2012; Melekoglu, 2011; Spencer et al., 2014). The findings of these studies have important implications for the successful identification of struggling readers who are at risk of RCD. The studies above support the 
use of a multistep and hybrid models of screening assessment over a single criterionbased screening (Gilbert et al., 2012; Spencer et al., 2014). Multistep hybrid screenings provide longitudinal stability as well as an individualized understanding of where the reading deficits lie.

Students with RD lack various developmental abilities and skill sets, such as language disabilities, cognitive abilities, and EF, that affect their ability to read and comprehend text. Some children with RD struggle with receptive and expressive oral language (Cartwright, 2012; Melekoglu, 2011). These skill deficits affect their ability to develop age or grade level vocabulary, knowledge of specific academic content, memory for word meanings, understanding the structure and syntax of sentences, and comprehending and drawing inferences (Cartwright, 2012; Melekoglu, 2011). Students with $\mathrm{RD}$ also demonstrate weaknesses in certain cognitive abilities that interfere with their ability to problem solve, reason, use working memory, and process information quickly (Cartwright, 2012; Melekoglu, 2011). Additionally, students with RD have certain weak EF abilities (i.e., cognitive flexibility, inhibition, and working memory) that affect problem solving, self-awareness, attention-regulation, regulation of academic achievement, and shifting or transferring skills from one task to another (Cartwright, 2012; Melekoglu, 2011). The trainable and malleable nature of EF makes EF reading interventions beneficial to incorporate in Tier 2 and Tier 3 planning. For this reason, providing RTI students with EF screenings and interventions can aid in improving students reading skills and abilities early on. 


\section{Theoretical Framework: Executive Functioning}

The cerebral cortex is the brain's outer layer of neural tissue that is responsible for the highest brain functions (Luria, 1973). Per Luria (1973), it is responsible for memory, attention, perception, thought, language and consciousness. The cerebral cortex is divided into three different lobes. Luria explains that each of these brain functioning units is hierarchical in structure and is made up of cortical zones that are built one above the other (Luria, 1973). Each cortical zone is composed of neurons and nerve cells that allow for synapses where communication occurs between neurons (Cartwright, 2012; Luria, 1973; MacNeil, 1987; Zelazo et al., 2016). A primary projection area receives or sends impulses to the surrounding area (Luria, 1973). A secondary projection-association area is where incoming information is processed and programmed to send messages from the brain to the different muscles, organs, and glands (Luria, 1973). The tertiary zones or overlapping area is responsible for complex mental activities that requires the integrated participation of various cortical structures (Luria, 1973). When functioning correctly these three unites or zones work together to regulate all human behaviors, from waking and sleeping, to hearing and seeing, to thinking and problem solving (Luria, 1973).

The first unit of brain functioning allows the nervous system to respond and adapt to perceived changes in the environment (Chan et al., 2008; Luria, 1973; MacNeil, 1987). The second unit of brain functioning allows the nervous system to process visual, auditory, gustatory, olfactory, vestibular, and general sensory information (Chan et al., 2008; Luria, 1973). The third unit of brain functioning is responsible for EF and is the focus of this theoretical framework. 
The third unit of brain functioning synchronizes the planning, organizing, programming, regulating, monitoring, executing, and verifying of behaviors (Chan et al., 2008; Luria, 1973). The anatomy of the third unit of brain functioning includes the frontal lobe of the brain. Neural activity passes through this unit to the motor cortex, where impulses are transmitted into motor routines and speech patterns. These impulses are projected to the pre-frontal cortex (PFC). The PFC is considered by Luria as a superstructure that regulates and controls mental activities and behaviors (Luria, 1973).

The PFC has been referred to as the conductor of an orchestra since it connects, coordinates and organizes neuro-transmitted information throughout various parts of the brain (Cartwright, 2012; Miyake et al., 2000; Zelazo et al., 2016). This function of the PFC is associated with many EF skills (i.e., cognitive flexibility, working memory, inhibitory control; Miyake et al., 2000; Zelazo et al., 2016). These connections to other parts of the brain occur primarily through white matter tracts and subcortical structures (i.e., basal ganglia which is important for learning patterns and routines, and the amygdala which controls emotions), which allows for quick goal-directed regulation to other parts of the brain associated with language, memory, attention, motor responses, learning patterns, routines, stress and emotional responses (Cartwright, 2012; Zelazo et al., 2016). The coordinating function of the PFC is what differentiates $\mathrm{EF}$ from other aspects of cognition.

Damage to the third unit can affect the regulatory control and organization of the impulses. Also, impaired functioning in the prefrontal cortex can affect the reciprocal relationship of different neurological pathways in the brain, leading to difficulties sustaining attention (Luria, 1973). 
The developmental course of EF begins during infancy and can be observed as attentional control, future-oriented problem solving and self-regulation of emotions. It continues through the preschool and school-age years to further mature and develop these abilities (Anderson, 2002; Isquith et al., 2004, Miyake et al., 2000). Executive functioning development has been compared by many researchers to a U-shaped curve. During the developmental process of EF there are important changes that occur at the end of the first year of life, between three and six years, and around puberty (McCloskey \& Perkins, 2012; Zelazo, Craik, \& Booth, 2003). While EF continues to develop into adulthood, it begins to deteriorate as one ages.

The first signs of EF as a conscious effort to control thought, action and emotions begin to emerge once an infant reaches the first year of life. Many babies from 8-12 months often play games where they are encouraged to search for a hidden object after a brief delay, a form of "hide and seek" or "peak a boo". Engaging in these games encourages the activation of EF skills as the baby needs to keep the object in his or her mind and perform one action (remove the blocking object) to perform another action (retrieve the toy; Zelazo et al., 2003). Participation in these types of games evidence the ability to perform an action to achieve a goal.

As children grow, preschoolers can begin thinking about past events and plan for future events, they are also able to consider several options and then select one. However, preschoolers' abilities to consciously control their thoughts, actions, and emotions are still limited. Once children develop into teenagers, EF becomes automated, where they can initiate a well-planned, organized, and flexible thought process that can be sustained over time. They can consider multiple possibilities, inhibit the inappropriate actions, and 
select the appropriate ones in pursuit of a goal, while monitoring the adequacy and efficiency of the process (Zelazo et al., 2016). The ability to self-monitor is a function of EF.

Conceptual framework: Connecting EF to reading. Researchers who study EF analyze the relationships between the brain, cognition and behavior (Christopher et al., 2012; Kim, Oines, \& Miyake, 2018; Miyake et al., 2000; Zelazo et al., 2016). The findings have demonstrated that individuals receive information through a neural process of hierarchically arranged regions of the PFC (Zelazo et al., 2016). The individual's brain then uses cognition to implement neurocognitive skills (e.g., cognitive flexibility, working memory, and or inhibitory control) and conduct an analysis of the information that leads to goal-directed problem solving and effective learning (Christopher et al., 2012; Cunningham \& Zelazo, 2007; Kim et al., 2018; Miyake et al., 2000; Zelazo, 2015; Zelazo et al., 2016). Individuals with poor EF abilities struggle to develop skills that allow for academic achievement, and many times require additional interventions and individualized instruction (Cunningham \& Zelazo, 2007; Zelazo, 2015; Zelazo et al., 2016).

Current research shows the importance of intact EF for successful school achievement (Blair \& Raver, 2015; Cartwright, 2012; Jacob \& Parkinson, 2015; Kavale \& Spaulding, 2008; Zimmerman, 2008). EF skills have little to do with rote memorizing and learning facts (i.e., vocabulary, spelling words, and times tables) and more to do with one's ability to reason, problem solve, and use the knowledge acquired from rote memory to make inferences and solve problems (Miyake et al., 2000; Zelazo, 2016). The attention 
and self-regulatory skills aid in learning because students can learn more efficiently and focus on important content and information.

Research shows that EF has significant direct and indirect influence on academic achievement, learning, and behavioral functioning (Fuchs et al., 2006; Kieffer, Vukovic \& Berry, 2013; Siegler \& Pyke, 2013; Vukovic et al., 2014). EF skills are credited with allowing students to sit, pay attention, memorize, follow rules, and shift from one concept or thought to another. Students who begin school with intact cognitive flexibility, working memory, and inhibitory control skills are better able to adjust to school and learn more easily (Christopher et al., 2012; Fuchs et al., 2006; Kieffer et al., 2013; Kim et al., 2018; Miyake et al., 2000; Siegler \& Pyke, 2013; Vukovic et al., 2014). These students are better organized, put attention to appropriate tasks and follow directions. Indirectly they are more optimistic about school, their learning potential, their teachers, and tend to exhibit appropriate behavioral regulations (Alloway et al., 2005; Blair \& Razza, 2007; Lyons \& Zelazo, 2011; U.S. Department of Education, 2014).

Recent research findings include strong ties between intact EF abilities and reading acquisition and comprehension (Blair \& Raver, 2015; Cartwright et al., 2016; Vukovic et al., 2014; Zelazo, 2016). Reading comprehension is a highly demanding task that requires sustained attention, simultaneous processing of information (i.e., cognitive flexibility, inhibition and working memory). Issues in reading acquisition and reading comprehension are affecting a significant number of elementary school students across the country (Cartwright et al., 2016; Christopher et al., 2012; Dahlin, 2011; GarciaMadruga, Elosua, Gil, Comez-Veiga, Vila, \& Orjales, 2013; Guajardo \& Cartwright, 2016; Kin et al., 2018). Multiple studies have found a positive relationship between EF 
and reading achievement. Researchers have found that all areas of reading place a heavy demand on EF (Cartwright, 2012; Christopher et al., 2012; Cutting et al., 2009; Fuchs et al., 2015; Keiffer et al., 2013; Miyake et al., 2000; Sesma et al., 2009). There is a connection between EF and early schooling success because of the self-regulatory and attentional skills required for learning. Also, EF plays a role in language acquisition and oral language comprehension, which are key elements found in pre-kindergarten and kindergarten curricula (Blair \& Razza, 2007; Kim et al., 2018; Welsh et al., 2010).

\section{Clinical Manifestations of EF Disorders and How they relate to RCD}

Research has shown that EF deficits are a prevalent characteristic of a variety of clinical disorders including SLD/RCD (Kolligian \& Sternberg, 1987; Semrud-Clikema et al., 2008). Children diagnosed with SLD/RCD may have poor regulation skills, such as planning, monitoring and revising during learning or problem solving. Many children with SLD/RCD have intact phonics and orthographic skills, however they struggle to coordinate the multiple processes involved in reading (Carlson et al., 2013; Garon, Bryson, \& Smith, 2008; Hughes, 2011; Jacques \& Marcovitch, 2010; Kibby, Marks, Morgan, \& Long, 2004; Meuwissen \& Zelazo, 2014; Zelazo et al., 2016).

Success in reading fluency and comprehension depends on EF abilities (Carlson et al., 2013; Garon, Bryson, \& Smith, 2008; Hughes, 2011; Jacques \& Marcovitch, 2010; Kibby et al., 2004; Meuwissen \& Zelazo, 2014; Zelazo et al., 2016). Reading is a complex process that requires the synchronization of many components (Cartwright, 2012). Current research has identified specific EF skills, including cognitive flexibility, working memory, and inhibitory control, as critical for reading comprehension (Carlson 
et al., 2013; Garon et al., 2008; Hughes, 2011; Jacques \& Marcovitch, 2010; Meuwissen \& Zelazo, 2014).

Cognitive flexibility. The first skill, cognitive flexibility, refers to an individual's ability to analyze information in multiple ways, such as considering multiple perspectives on an issue or multiple ways to solve a problem (Carlson et al., 2013; Christopher et al., 2012; Garon et al., 2008; Hughes, 2011; Jacques \& Marcovitch, 2010; Kim et al., 2018; Meuwissen \& Zelazo, 2014; Miyake et al., 2000). In a study conducted by Jacob and Parkinson (2015), children ages 2-18 were assessed in multiple aspects of EF, including cognitive flexibility, working memory, inhibitory control, sustained attention, focused attention, and motor response. The results of the assessment were compared to the students' functioning in reading at the school level. The results demonstrated that the highest correlations to reading achievement were attention (inhibition) and cognitive flexibility (shifting; Jacob \& Parkinson, 2015).

To better understand the impact that cognitive flexibility has on reading acquisition and comprehension, Kelly Cartwright (2012) conducted a study of second to fourth grade struggling readers. The goal of the study was to determine if cognitive flexibility training could help improve reading comprehension (Cartwright, 2012). First, Cartwright developed a method to assess the students' level of cognitive flexibility by having students sort through four sets of 12 printed words using sounds and meanings (Cartwright, 2012). Students were provided five cognitive flexibility training sessions. Reading comprehension levels were assessed by the Woodcock Reading Mastery TestRevised using a pre-test post-test comparison. The results indicated improvements in sound-meaning, cognitive flexibility, and reading comprehension after completing the 
intervention (Cartwright, 2012). The improvements that the students demonstrated have important implications for the reading instruction of elementary age students because it supports the use of EF interventions.

More recently, Cartwright and colleagues (2016) conducted a two-part study that assessed the EF cognitive flexibility abilities of first and second grade students struggling in reading and then provided a teacher delivered cognitive flexibility intervention. The first part of the study evaluated and compared the cognitive flexibility levels of 24 students with RCD with the control group of 24 students with typical reading comprehension. The results indicated that the students with RCD had less cognitive flexibility than the control group. They specifically struggled with coordinating flexibility to switch between the phonological and semantic aspects of printed words.

The second part of this study was a longitudinal study that looked at the implementation of cognitive flexibility Tier 2 interventions or teaching strategies with 48 third grade students. The interventions were provided by the students' third grade teachers for one school year. The results indicated that the students more than doubled their reading comprehension growth in the spring after receiving the targeted interventions (Cartwright et al., 2016).

The study conducted by Cartwright and colleagues (2016) is significant because it helps teachers teach students who are struggling in reading comprehension even though they have intact decoding and fluency skills. Traditional concepts of RCD have led teachers to focus much of their teaching and interventions on decoding skills and linguistic comprehension. Many times, students with RCD are overlooked because their fluent reading masks their comprehension difficulties. However, these students' 
inflexible focus on word-level features of the text make them unable to focus on the meaning of the words (Cartwright et al., 2016). In addition, students with RCD's inflexible reading style impacts their ability to discover semantic relationships between words, infer meaning from context, grow their vocabulary over time, and make inferences from the text for prior knowledge (Cartwright et al., 2016). The cognitive flexibility training provided throughout the second part of the study that includes the longitudinal piece teaches students to manage multiple aspects of a task as well as switch between them. For example, in reading, students learned to manage phonological and semantic processes while reading (Cartwright et al., 2016).

Researchers from Christopher Newport University were interested in learning more about improving cognitive flexibility following the theory of mind training (Guajardo \& Cartwright, 2016). They completed a longitudinal study with 31 children. Students were assessed when they were 3-5 years of age using performance assessments that measured language comprehension, working memory, cognitive flexibility, and first order false belief understanding. They were later assessed at age 6-9 on false belief, cognitive flexibility, reading comprehension, and reading awareness. Students reading abilities and EF abilities were compared. The results demonstrated gains in the students reading abilities for those who received EF interventions. The results further support the importance of cognitive flexibility and reasoning for successful reading comprehension.

Karbach and Kray (2009) demonstrated positive results after providing cognitive flexibility training. The researchers looked at improving transfer and cognitive flexibility abilities in 56 participants. The study was a longitudinal study that looked at lifespan changes. The participants ranged from three age groups 8-10, 18-26, and 62-76. The 
participants were provided with training using task-switching procedures. The intervention improved the participants' abilities to transfer and switch tasks. Researchers also found improvements in working memory and fluid reasoning, particularly in the children and adults (Karbach \& Kray, 2009). All areas that have proven to be critical abilities for reading comprehension success.

Working memory. Another EF skill that greatly impacts reading acquisition and comprehension is working memory, which refers to retaining information, as well as manipulating it to solve problems (Carlson et al., 2013; Garon et al., 2008; Hughes, 2011; Jacques \& Marcovitch, 2010; Meuwissen \& Zelazo, 2014; Miyake et al., 2000). Reading comprehension asks that the reader store recently decoded text information to process knowledge, make inferences, and construct meaning (Christopher et al., 2012; GarciaMadruga et al., 2013; Kim et al., 2018). One example in reading is the integration of various concepts and ideas to comprehend text and answer questions about text (Carlson et al., 2013; Garon et al., 2008; Hughes, 2011; Jacques \& Marcovitch, 2010; Meuwissen \& Zelazo, 2014).

In 2011, Dahlin conducted a study that looked at the connection between working memory and reading achievement. The goal of the study was to look at the effects of working memory training on working memory measures, and if training could improve reading comprehension. The study took place in Stockholm and included 57 Swedish special education students grades 3-5. Of the 57 participants, 42 students made up the experimental group and 11 students made up the control group, who did not receive any additional interventions. The students in the experimental group were provided with a working memory intervention daily for 30-40 minutes over a 5-week period. The training 
was provided by means of a computer program that provided students with visual spatial and verbal working memory training. Three sessions of assessment were administered to measure the effectiveness of the intervention. Students were given a battery of assessments that measured memory and reading before, right after, and six to seven months after the intervention period. The results support the notion that working memory is an important ability for successful reading as word reading, reading comprehension as well as working memory scores increased significantly in all experimental students when compared to the control group. In addition, these results help support the important role that working memory training plays in the development of literacy (Dahlin, 2011).

A study conducted by Christopher and colleagues (2012) explores the connection between EF and word reading and reading comprehension. The researchers studied the connection between the EF abilities of Working Memory, inhibition, and processing speed with word reading and reading comprehension (Christopher et al., 2012). Researchers were interested in gaining a better understanding if each EF construct is a predictor of word reading and reading comprehension. The study looked at 483 eight to 16-year-old students who were evaluated during four, 2.5-hour performance-based testing sessions that included working memory, processing speed, inhibition, listening comprehension, word reading and reading comprehension subtests. After analyzing the extensive data, the results found a correlation between reading and working memory and processing speed (Christopher et al., 2012). Both working memory and processing speed abilities were found to be predictors of word reading and reading comprehension abilities (Christopher et al., 2012). 
A study by Garcia-Madruga and colleagues further explored the role of the EF ability of working memory and reading comprehension (2013). The goal of the study was to determine if working memory interventions are effective in improving reading comprehension. The study included two parts where interventions were delivered to third grade students and empirically tested to determine their effectiveness. The goal of the first experiment was to assess the effectiveness of an intervention program that was meant to improve the reading comprehension of 31 third grade students by teaching EF strategies such as focusing, switching, long-term memory, and inhibition. The researchers were also interested seeing if the interventions also improved working memory abilities (Garcia-Madruga et al., 2013). The experimental group received interventions daily for 50 minutes over a four-week period. Researchers used a pre-test/ post-test to determine the effectiveness of the interventions. The results of the first experiment were positive for improved reading comprehension after the intervention period (Garcia-Madruga et al., 2013). The results support the hypothesis that it is possible to develop interventions that improve reading comprehension by teaching EF strategies and improved EF functioning. The second experiment was similar to the first however the researchers added pre- and post-test data that measured EF ability of working memory as well as intelligence. The interventions were provided to 46 third grade students on ten days over a four-week period. The results demonstrated a significant increase in reading comprehension as well as working memory, inferencing and integration (Garcia-Madruga et al., 2013).

A study by Sesma and colleagues explored the need of EF interventions for successful reading comprehension (2009). Sesma and colleagues discovered that while word recognition deficits (WRD) were considered the leading cause of RCD, the 
significance of EF had not yet been fully explored (2009). The researchers sought to investigate the impact of the EF constructs of working memory and planning on reading comprehension (Sesma et al., 2009). The study Sesma et al., looked at 60 children with WRD and/or RCD ages 9-15 years old. A battery of psychoeducational testing was designed and administered to each child in the study. The results indicated that both verbal working memory and planning skills significantly contributed to improved reading comprehension (Sesma et al., 2009).

The studies presented above support and the positive influence that intact working memory has on successful reading. Specifically, the inclusion of working memory EF interventions when targeting reading comprehension deficits. The main difference between the reading interventions described above and commonly used reading interventions is that the ones listed in these studies include the training of the conscious control of EF (Garcia-Madruga et al., 2013). Garcia- Madruga and colleagues describe their program as "not a reading comprehension program aimed to instruct readers on particular reading comprehension skills or strategies... From the first to the last session, our training sought an improvement in students' mental activation" (Garcia-Madruga et al., 2013, p. 170).

Research in EF training that focuses on improving working memory has historically proven to show success in reading comprehension (Zelazo et al., 2016). As a result, there are various existing programs that have positive effects on increasing working memory: Tools of the Mind Program, Open the World of Learning, Promoting Alternative Thinking Skills (PATHS), and the Chicago School Readiness Project (CSRP), to name a few (Zelazo et al., 2016). These programs have demonstrated positive 
effects on EF abilities and researchers have seen changes in memory, reasoning, reading, math, language, emotional regulation, attention control, reduced behavioral problems, improved social functioning, and increased inhibition control (Barnett et al., 2008; Blair \& Ravner, 2014; Chooi \& Thompson, 2012; Espinet, Anderson, \& Zelazo, 2013; Karbach \& Kray, 2009; Schmitt et al., 2015; Thompson et al., 2013; Zelazo et al., 2016). Overall, studies have demonstrated that working memory training has both short-term and long-term effects on improving working memory, fluid reasoning, and academic functioning (Melby \& Hulme, 2013; Schmitt et al., 2015; Schwaighofer, Fisher, \& Buhner, 2015; Weicker, Villringer, and Thone-Otto, 2016; Zelazo et al., 2016).

Inhibitory control. Reading comprehension is also impacted by the EF skill of inhibitory control, which refers to the ability to control and regulate where one places his or her attention (Carlson et al., 2013; Christopher et al., 2012; Garon et al., 2008; Hughes, 2011; Jacques \& Marcovitch, 2010; Kim et al., 2018; Meuwissen \& Zelazo, 2014; Miyake et al., 2000). Inhibitory control also refers to the ability to ignore distractions and control impulses. Inhibition can be defined as the ability to suppress or remove outdated information and ignore irrelevant stimuli to maintain focus on a goal (Christopher et al., 2012).

A study by Keiffer and colleagues further supports the impact of EF on reading comprehension (Keiffer et al., 2013). Their study looked at 120 fourth grade students attending two public schools in New York City and compared their EF abilities of attention shifting and inhibitory control to reading comprehension performance. Students were assessed in reading comprehension (using the Gates-Macginitie Reading Comprehension test), attention shifting (using the Wisconsin Card Sorting Test), 
inhibition (using a Researcher developed measure), language comprehension (using the WJ-III), and word reading (using the WJ-III). The 120 students were individually assessed using the above-mentioned battery in the winter of their fourth-grade year. Results were analyzed and the findings connected the EF abilities of inhibition and attention shifting to success in reading comprehension (Keiffer et al., 2013).

A study by Locascio and colleagues further explored the EF role of inhibitory control and reading (2010). The study looked at 86 children ages 10-11 and grouped them into average readers, word recognition deficits (WRD), and specific reading comprehension deficits (S-RCD). The students were given a battery of EF tests (Locascio, Mahone, Eason, \& Cutting, 2010). The results showed that the WRD group showed EF deficits in inhibition, working memory, and planning (Locascio et al., 2010). The S-RCD group struggled mostly with inhibition used for planning and organization (Locascio et al., 2010).

In a study by Espinet and colleagues, researchers explore the benefits of reflection training to increase the EF ability of inhibition control (2013). The goal of reflection training is to help students control impulsivity, the idea is to pause and reflect before acting (Espinet, Anderson, \& Zelazo, 2013; Zelazo et al., 2016). Espinet and colleagues (2013) conducted a study where they provided training for participants in the importance of pausing and reflecting. Participants were provided with sorting activities, where they were asked to sort illustrated cards (Espinet et al., 2013). Throughout the session, participants were trained to wait and pause, reflect, form concepts, and respond flexibly (Espinet et al., 2013). The control group was provided with minimal feedback. The results demonstrated significant changes in the intervention groups behaviors, showing 
that a 15-minute targeted intervention can have a significant impact in improving a student's EF abilities of reflection and cognitive flexibility (Espinet et al., 2013).

Overall, EF abilities are associated with various aspects of comprehension (Alloway et al., 2009; Booth, Boyle, \& Kelly, 2010; Christopher et al., 2012; Geary, 2011; Kim et al., 2018). When students have EF deficits, they can experience both direct (cognitive processing) and indirect (behavioral regulation) impacts on learning (Alloway et al., 2009; Booth, Boyle, \& Kelly, 2010; Geary, 2011). There is still much to learn about the precise EF deficits that affect each aspect of reading. There are multiple influences on EF development and the multiple neurological pathways that must occur for intact EF functioning. However, as a result of the malleable and teachable aspect of $\mathrm{EF}$, continued research in this area will improve and individualize the interventions available to students who are struggling with RCD.

\section{EF Assessment in Children}

The assessment of EF in children is a relatively new construct. For most of the $20^{\text {th }}$ century, clinicians believed that the frontal lobe of the brain was a section that was developed during adulthood, making assessment of EF a practice limited to adults (Cartwright et al., 2012; Zelazo et al., 2016). It was not until the 1980s and 1990s that clinicians discovered that brain development spans from infancy through adulthood (Cartwright et al., 2012; Zelazo et al., 2016). During the 1990s researchers focused many of their studies on the EF skills and abilities of preschool and school aged children to develop assessments that could measure all aspects of EF. There was a shift in thinking that moved the study and concept of EF from the clinical setting, to the real-world setting. Practitioners began to view EF as an important component of cognitive 
development and self-regulation that is imperative for social and academic success (Moffitt et al., 2011; Zelazo et al., 2016)

The assessment of EF has historically been a challenge for practitioners because of the complex nature of the construct (Isquith Crawford, Espy, \& Gioia, 2005; Zelazo et al., 2016). One of the biggest challenges in the assessment of EF is gaining an understanding of how the individual's EF deficits impact real-world everyday activities (Isquith et al., 2005). There are a variety of performance-based instruments that practitioners use to measure EF (e.g., the Developmental Neuropsychological Assessment [NEPSY], the Naglieri and Das, the Cognitive Assessment System, Child Category Test). Many of these tests have proven to be effective in measuring certain aspects of EF, however the structured one-to one controlled setting, with minimal distractions in which the test is administered interferes with its ability to assess all aspects of EF (Zelazo et al., 2016). Also, many times the examiner provides support and encouragement, as well as planning and initiating activities for the examinee that also effect the validity of the test (Zelazo, 2016). Test developers strive to attain ecological validity. Ecological validity is a term used to describe neurological testing tools that can establish a functional and predictive relationship between students' performance on a neurological test and their behavior in a variety or real-world settings (Isquith et al., 2005). Thus, much of the research is demonstrating that there is a gap between the performance on traditional measures of EF and real-life functioning (Chan et al., 2008; Zelazo et al., 2016).

Best practices indicate that the use of structured behavior rating scales allow for the systematized observation of the child's behavior at home and/or in school by parents and/or teachers (Chan et al., 2008; Gioia et al., 2001; Zelazo, 2016). These rating scales 
provide reliable reports regarding the child's everyday manifestations of EF deficits by providing valuable real-world information on the individual's EF functioning strengths and weaknesses (Chan et al., 2008; Gioia et al., 2001; Zelazo, 2016). Guided observation of behavior rating scales for EF assessment has been utilized by clinicians for decades as common practice and is a well-proven method for the assessment of EF (Chan et al., 2008; Gioia et al., 2001; Zelazo, 2016). Performance-based EF tasks measure children's cognitive skills directly, and EF rating scales measure the behavior enactment of EF skills in daily life environments (Gioia et al., 2001; Zelazo et al., 2016). When the rating scales are given to parents, teachers, and adolescents, the results provide a depiction of that student's EF functioning in multiple contexts (i.e. playground, classroom, lunchroom, standardized testing, home).

A study conducted by Lamberts and colleagues considered the ecological validity of behavior questionnaires to measure EF (2010). The study looked at 92 participants who were divided into two groups, brain injured and a control group (Lamberts, Evans, \& Spikeman, 2010). Participants were given a battery of EF assessments that included both questionnaires and structured EF assessments. The results demonstrated that the questionnaires were good predictors of EF functioning because they demonstrated stronger ecological and concurrent validity when compared to the performance-based tests (Lamberts et al., 2010).

More recently, a study conducted by Nilsen and colleagues explored the validity of preschool students EF skills using rating scales (2017). The goal of Nilsen's study was to develop a valid questionnaire that effectively measured EF in young children (Nilsen, Huyder, Mcauley, \& Liebermann, 2017). Nilsen and colleagues see the importance in the 
use of questionnaires rather than laboratory control-based assessments when measuring EF because they integrate the child's behaviors in their environment which allows for a more global picture of the EF functioning than the performance-based tests (Nilsen et al., 2017). Rating scales and questionnaires allow for the collection of data in an efficient way from multiple sources over different contexts in different times, increasing the ecological validity of the test (Nilsen et al., 2017). While there are some existing EF rating scales such as the BRIEF-2, Nilsen and colleagues find them to be general and wanted to create a more detailed and specific measure of EF in younger children. In this study, researchers looked at the EF abilities of 42 children ages three to five using the newly designed rating scale, rating of everyday executive functioning (REEF) and the BRIEF-2 (Nilsen et al., 2017). The researchers compared the results and found correlations between the two rating scales. The results found that the new rating scale demonstrated internal consistency and validity (Nilsen et al., 2017).

Toplak and colleagues (2013) conducted an examination of 20 studies that looked at the connection between and the association between performance-based measures of EF and rating measures of EF. After reviewing various studies that looked at rating scales such as the BRIEF-2, childhood executive functioning inventory (CHEXI), and behavioral assessment of dysexecutive syndrome (BADS), results indicated that the correlation between performance-based measures and rating measures of EF is weak, indicating that both measure different aspects of EF. The performance-based tests measured more processing efficiency and the rating measures more the behavioral application of EF abilities to accomplish goals and solve problems (Toplak, West, \& Stanovich, 2013). Researchers concluded that while both forms of EF assessment are 
valuable, practitioners cannot assume that they capture the same level of analysis and thus are not transposable as equivalent measure of EF (Toplak et al., 2013).

\section{Summary}

The purpose of this literature review was to discuss the relationship between EF and RCD to make a case for EF screenings in the RTI process. Research shows that many students who struggle with reading comprehension have deficits in EF. Much of the research on EF has demonstrated that it is malleable and trainable. As a result, children who are provided with quality early education that fosters the development of EF abilities tend to have more success in school. In addition, there is much research that supports the implementation of certain interventions and training programs to improve and increase EF abilities. There are several interventions and training programs that focus on improving working memory, self-regulation, emotional regulation, cognitive flexibility, inhibition, and behavior control. EF training has proven to have a positive effect on educational outcomes and success.

Since EF is a malleable and teachable construct, interventions that focus on improving EF abilities may aid in improving success for students with RCD. The BRIEF2 is a proven individualized EF assessment tool that provides valuable insight into each student's EF strengths and weaknesses, allowing for individualized and targeted Tier 2 and Tier 3 interventions. The research presented above identifies three EF constructs that affect reading comprehension, cognitive flexibility, working memory, and inhibition. In addition, the research supports the notion that interventions that target these areas transfer to improved reading comprehension abilities. However, there are no published studies that look at the relationship between these EF constructs as measured by the BRIEF-2 
and reading comprehension abilities as measured by the iReady reading comprehension scores of elementary school students. This gap in the literature provided an opportunity to explore the relationship between students' EF abilities and RCD skills for improving RTI screenings to provide valuable data towards designing more effective interventions. 


\section{CHAPTER III}

\section{Method}

The present study investigated the relationship between executive functioning (EF) and reading comprehension deficits (RCD). This chapter provides information on the participants, the setting, materials used, independent and dependent variables, data collection system, experimental design procedures, and data analysis. The aim was to explore the profile of elementary school students' EF strengths and weaknesses as they affect reading comprehension to offer data to improve the individualization of interventions implemented in the response to intervention (RTI) tiers. In addition, the researcher explored the predictive relationship between EF screenings on reading comprehension achievement. The exploration occurred through the quantitative analysis of each student's reading comprehension achievement data and EF ability scores using correlations and regressions. Additionally, language skills data were collected and used as a control and covariate to further clarify if EF abilities directly contribute a significant amount of variance to reading comprehension.

\section{Hypotheses}

Executive functioning abilities play a significant role in reading comprehension (Carlson et al., 2013; Garon et al., 2008; Hughes, 2011; Jacques \& Marcovitch, 2010; Meuwissen \& Zelazo, 2014). The present study investigated the following hypothesis statements regarding EF strengths and weaknesses for a group of elementary school-age students attending a large urban public-school district in the south-east United States (US). 
$\mathrm{H}_{01}$ : there is not a significant difference in EF, according to the BRIEF-2 TRF inhibition, cognitive flexibility, and working memory scores, between the grade level readers (Tier 1), at risk readers (Tier 2) and poor readers (Tier 3), using the iReady reading assessment (reading comprehension).

$\mathrm{H}_{1}$ : There is a significant difference in EF abilities between grade level readers (Tier 1), at risk readers (Tier 2), and poor readers (Tier 3).

$\mathrm{H}_{02}$ : Inhibition, cognitive flexibility, and working memory are specific EF abilities that do not correlate with reading comprehension skills.

$\mathrm{H}_{2}$ : There is a significant correlation between EF, using the BRIEF-2 TRF inhibition, cognitive flexibility, and memory scores, and reading comprehension for grade level readers (Tier 1), at risk readers (Tier 2) and poor readers (Tier 3), using the iReady reading assessment (reading comprehension).

$\mathrm{H}_{03}$ : Inhibition, cognitive flexibility, and working memory are EF abilities that do not significantly predict reading comprehension.

$\mathrm{H}_{3}$ : Inhibition, cognitive flexibility, and working memory EF abilities significantly predict reading comprehension in average (Tier 1), at risk readers (Tier 2) and poor readers (Tier 3), using the iReady reading assessment (reading comprehension).

$\mathrm{H}_{04}$ : Inhibition, cognitive flexibility, and working memory are EF abilities that do not predict reading comprehension after controlling for language skills.

$\mathrm{H}_{4}$ : Inhibition, cognitive flexibility, and working memory EF abilities predict reading comprehension, after controlling for language, using the iReady reading assessment (vocabulary) in grade level (Tier 1), at risk readers (Tier 2) and poor readers (Tier 3). 


\section{Participant Information}

The study included participants between the ages of 7.0 and 10.0; this age group was selected because these are the early stages of EF development and the early instruction of reading and reading comprehension (Cartwright, 2012; Christopher et al., 2012; Kim et al., 2018). Ninety-five participants were recruited so that the researcher could rule out exclusionary factors and still have enough participants per tier. A minimum of 80-90 participants were needed to obtain an effect size of .5 . This is the effect size generated in the power analysis on the basis of the prior literature to determine the sample size (Cartwright, 2012; Christopher et al., 2012; Kim et al., 2018). The researcher was able to secure 87 participants who consented and did not have exclusionary factors. Participants were elementary school students in the primary grades attending a large urban school district in the southeast US. The researcher distributed an informational flyer for educators to recruit potential participants. The informational flyer was sent to district principals to advertise to their teachers. The flyer was submitted to the Florida International University (FIU) Institutional Review Board (IRB) and district public school IRB committee for approval prior to distribution. (IRB \# 18-0111)

The researcher spoke to parents and teachers to rule out exclusionary criteria, which included age, traumatic brain injury, psychiatric disorder, and/or significant developmental delays. Students with psychiatric disorders such as anxiety, depression, bipolar disorder or schizophrenia were not included in the study. In addition, students with severe motor, language, and/or cognitive delays were not included in the study. The presence of any of the listed disorders or delays could affect the students' learning and 
reading comprehension abilities and thus skew the results derived from the study. In addition, the researcher analyzed the Spring 2018 iReady diagnostic reading comprehension domain scaled score and grade level rank and the vocabulary domain scale scores. Participants who fulfilled the selection criteria for this study were divided into three groups: Tier 1, Tier 2, and Tier 3. Data were collected only for students whose parents provided consent.

The Tier 1 group included 35 children who scored on grade level on the iReady diagnostic reading comprehension assessment. These are students who are accessing their education and responding to Tier 1 interventions in the general education setting without the help of individualized interventions. These students received 90 minutes of reading instruction daily. The Tier 2 group included 36 children who scored one year below grade level on the iReady diagnostic reading comprehension assessment. These were students who required reading interventions to supplement and support the general whole group instruction. Most of these students received 30 additional minutes of reading instruction beyond the 90-minute reading block. The additional 30 minutes are targeted and involve smaller groups. The Tier 3 group included 16 children who scored two years below grade level on the iReady diagnostic reading comprehension assessment. These are students who require targeted reading interventions to supplement and support the general whole group instruction. Most of these students received 30 minutes of targeted evidence-based interventions; however, they were not making gains. Thus, they were provided with oneto-one reading instruction daily during their 90-minute reading block or 30-minute intervention period. Some students at Tier 3 were diagnosed with a specific learning disability (SLD) in reading and had individualized education plans (IEPs) to further 
address their reading difficulties. Figure 1 outlines the description of the different RTI tiers for the present study (see Table 1).

Table 1

RTI tiers -2017-2018 iReady Scale Score Placement Tables (Curriculum associates, 2017)

\begin{tabular}{llcl}
\hline RTI Tiers & Grade & Reading Comprehension Scaled Score & Description \\
\hline Tier 1 & $1^{\text {st }}$ & $480-536$ & On grade level \\
& $2^{\text {nd }}$ & $537-560$ & \\
& $3^{\text {rd }}$ & $561-602$ & $6-10$ months \\
Tier 2 & $1^{\text {st }}$ & $434-479$ & \\
below & & $491-536$ & \\
& $2^{\text {nd }}$ & $514-560$ & $1-2$ years \\
Tier 3 & $3^{\text {rd }}$ & $100-433$ & \\
below & & $100-490$ & \\
& $2^{\text {st }}$ & $100-513$ & \\
\hline
\end{tabular}

Inclusion/exclusion criteria. Data regarding children seven to ten years of age who and were receiving reading instruction through RTI Tier 1, Tier 2, or Tier 3 were included in the study. Students were not selected to participate in the study if they met criteria for any psychiatric disability or had experienced a traumatic brain injury or any significant developmental delays. It was important to rule out for these exclusionary 
criteria to ensure that there was not another reason to account for the students learning difficulties in reading. Figure 1 displays the procedural steps that were followed for the selection of the sample (see Figure 1).

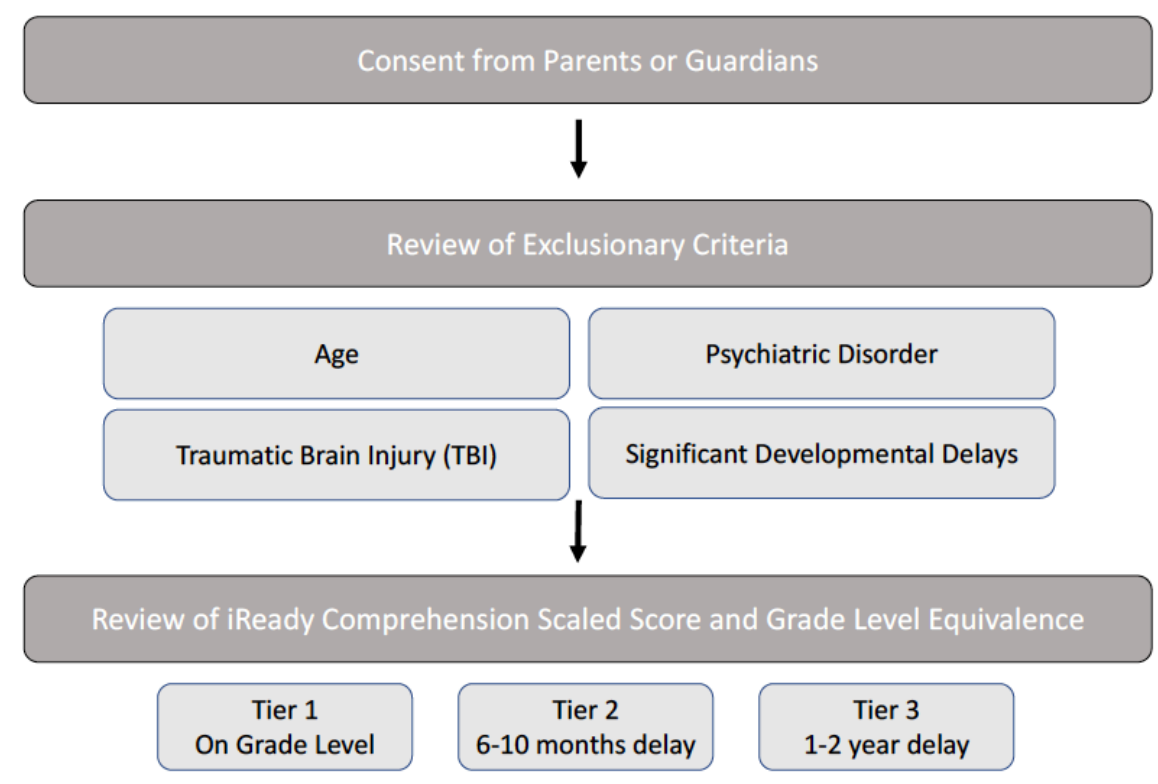

Figure 1. Procedural steps for sample selection

\section{Data Collection Instruments}

The data collected for this study included gathering the scores for each student's reading comprehension achievement assessment, vocabulary assessment, as well as scores for each student's EF abilities assessment. Demographic data such as age, gender, and race were collected from the student's guardians. The data collection tool that was used to gather data on each students' reading comprehension achievement was the Spring 2018 iReady reading placement-comprehension literature scores. The data that were collected to measure the students' language skills was the Spring 2018 iReady vocabulary score. The data collection tool that was used to gather data on each students' EF abilities was the BRIEF-2 rating scale inhibition, working memory, and shifting scores. 
iReady. iReady is a tool that provides ongoing diagnostic assessment data to determine reading levels for students. The diagnostic assessments are built on the common core state standards (iReady user guide, 2015). The diagnostic data provides a global score as well as grade level reading domain scores in foundational skills, vocabulary, comprehension - informational text, and comprehension - literary text. The scoring is provided in scaled scores and grade level equivalents. Students are provided three diagnostic assessments per year to track their reading levels, to determine tier placement for RTI, and determine response or lack of response to instruction. The reading diagnostic assessment took 30-60 minutes to administer and provided scoring on four grade level domains; foundational skills, vocabulary, comprehension- informational text, and comprehension literacy text. The researcher focused on the comprehension literacy text grade level domains and the vocabulary domain. Figure 3 provides a description of each of the four domains and what skills are assessed.

The validity for iReady was explored through several studies that explored correlations to state and consortium assessments. iReady diagnostic demonstrated correlations of .81 to the $2015-2016$ New York State language arts assessment and a correlation of .84 to the Florida language arts assessment (Curriculum Associates, 2017). 
Table 2

iReady Reading Assessment Domains and Skills (iReady user guide, 2015)

Domain (Grade-Level Difficulty of

\begin{tabular}{|c|c|c|}
\hline \multicolumn{2}{|l|}{ Questions) } & Skills Assessed \\
\hline \multirow{3}{*}{$\begin{array}{l}\text { Foundational } \\
\text { Skills }\end{array}$} & $\begin{array}{l}\text { Phonological Awareness } \\
\text { (Grades K-1) }\end{array}$ & $\begin{array}{l}\cdot \text { Rhyme Recognition } \\
\text { - Phoneme Identity and Isolation } \\
\text { - Phoneme Blending and Segmentation • Phoneme Addition } \\
\text { and Substitution } \\
\text { - Phoneme Deletion }\end{array}$ \\
\hline & Phonics (Grades K-4) & $\begin{array}{l}\cdot \text { Letter Recognition } \\
\cdot \text { Consonant Sounds } \\
\cdot \text { Short and Long Vowels } \\
\cdot \text { Decoding One- and Two-Syllable Words } \\
\text { Diphthongs } \\
\cdot \text { Vowel Patterns } \\
\cdot \text { Decoding Longer Words }\end{array}$ \\
\hline & $\begin{array}{l}\text { High-Frequency Words } \\
\text { (Grades K-3) }\end{array}$ & - Words from Dolch and Fry lists \\
\hline \multicolumn{2}{|c|}{ Vocabulary (Grades K-12) } & $\begin{array}{l}\text { - Academic and Domain Specific Vocabulary } \bullet \text { Word } \\
\text { Relationships } \\
\text { - Word-Learning Strategies } \\
\text { - Use of Reference Materials } \\
\text { - Prefixes, Suffixes, and Word Roots }\end{array}$ \\
\hline
\end{tabular}




\begin{tabular}{|c|c|}
\hline $\begin{array}{l}\text { Comprehension: Informational Text } \\
(\text { Grades K-12) }\end{array}$ & $\begin{array}{l}\text { - Author's Purpose } \\
\text { - Categorize and Classify } \\
\text { - Drawse and Effect } \\
\text { - Fact and Opinion } \\
\text { - Main Idea and Details } \\
\text { - Message } \\
\text { - Summarizing/Retelling } \\
\text { - Text Structure } \\
\text { - Determining Word Meaning } \\
\text { - Compare and Contrast Across Different Texts and } \\
\text { Mediums • Analysis of Close Reading of a Text } \\
\text { - Citing Textual Evidence }\end{array}$ \\
\hline $\begin{array}{l}\text { Comprehension: Literary Text (Grades } \\
\mathrm{K}-12)\end{array}$ & $\begin{array}{l}\cdot \text { Point of View and Purpose } \\
\text { - Cause and Effect } \\
\text { - Frawing Conclusions/Making Inferences } \\
\cdot \text { Story Elements } \\
\text { - Summarizing/Retelling } \\
\text { - Theme/Mood } \\
\text { - Analyzing Character } \\
\text { - Determining Word Meaning } \\
\text { Mediums - Analysis of Close Reading of a Text } \\
\text { - Citing Textual Evidence }\end{array}$ \\
\hline
\end{tabular}


BRIEF-2. The Behavioral Rating Inventory of Executive Functions, Second Edition (BRIEF-2) scales are currently the most utilized and researched measure of EF (Gioia, Espy, \& Isquith, 2015; Roth et al., 2013; Toplak et al., 2013; Zelazo et al., 2016). The BRIEF-2 is a parent, teacher, and self (when applicable) rating scale designed to assess the behavioral manifestations of EF in children ages 5-to-18 years old. For this study, the researcher used the teacher questionnaire as it is more relevant to exploring the research questions.

The BRIEF-2 rating scales are comprised of a demographic sheet and 63 threepoint Likert scale items. The items are behavioral descriptors of children, and are rated as 1 (Never observed), 2 (Sometimes observed), and 3 (Often observed). The 63 items create three index scales and nine clinical scales. The raw scores for each of the scales and indexes are converted to T-scores with a mean of 50, and a standard deviation of 10. Age level norms were used for this study to compare each student's EF functioning to that of other students their age in the sample size. Higher T-scores are indicative of higher deficits (Gioia et al., 2015). More specifically, T-scores higher than or equal to 65 are considered clinically significant and suggest a deficit in that area (Gioia et al., 2015).

The three index scales include the Behavioral Regulation Index (BRI), the Emotional Regulation Index (EMI), and the Cognitive Regulation Index (CRI). The BRI includes the inhibit and self-monitor scales which measure impulse control and the effect of one's behaviors on others (Gioia et al., 2015). The EMI includes the shift and emotional control scales which measure cognitive flexibility, transitioning, and the ability to modulate and control one's emotions (Gioia et al., 2015). The CRI includes the initiate, working memory, plan/organize, task monitor, and organization of materials scales. The 
CRI index measures the ability to begin a task and the self-discipline to initiate work or projects (Gioia et al., 2015). It also measures the ability to hold information in the immediate awareness and use it with the purpose to solve a problem or complete a task or activity (Gioia et al., 2015). Additionally, the CRI measures the ability to set goals, create the appropriate steps to complete a task or reach a goal, and understand main ideas and key concepts (Gioia et al., 2015). Further, task monitoring can be used to monitor and check throughout to ensure that tasks are being completed correctly. Lastly, the CRI measures one's ability to keep things organized (Gioia et al., 2015). (See Figure 2.) The BRIEF-2 also includes three validity scales that measure negativity and inconsistency or responses (Gioia et al., 2015).

The study specifically examines three aspects of EF that research has demonstrated have a positive relationship with reading comprehension. These include inhibition, working memory, and cognitive flexibility. The students' inhibition, working memory, and cognitive flexibility abilities were measured using the inhibit, working memory, and shift scales on the BRIEF-2 TRF. Each scale included eight items. 


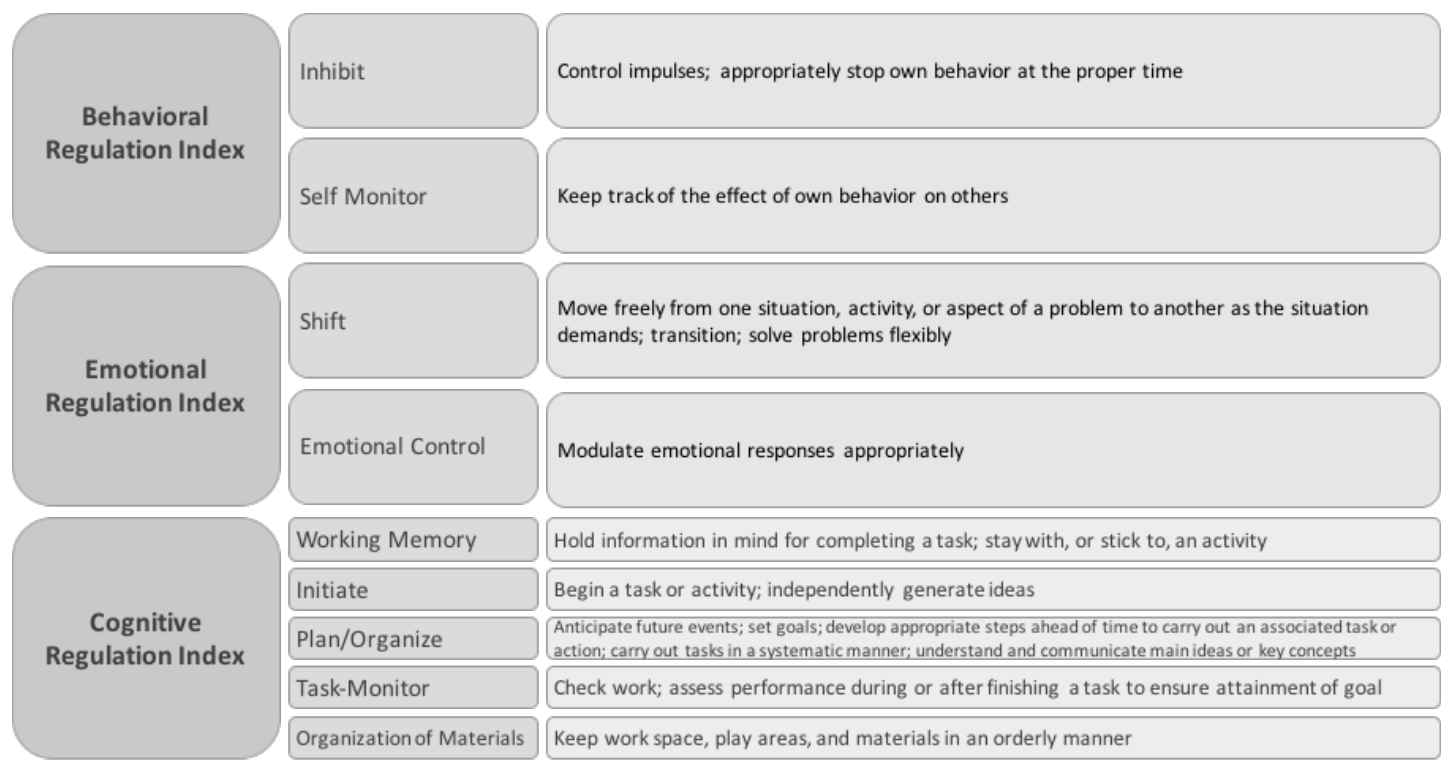

Figure 2. BRIEF-2 Description of the indexes and scales (Gioia et al., 2015)

In creating the BRIEF-2, Gioia and colleagues reviewed the literature on EF in children and conducted several studies to explore the psychometric properties of the instrument. Reliability and internal consistency were found to be high with index coefficients above 90 (Gioia et al., 2015). The effect size for the interrater reliability between two teachers were moderate with an overall moderate mean correlation of .56 for the clinical sample. Also, test-retest reliability correlation coefficient for teachers was .82 over an average interval of 2.8 weeks (Gioia et al., 2015).

The validity of the BRIEF-2 to measure content validity, agreement was sought among several pediatric neuropsychologists (Gioia et al., 2015). The clinicians were asked to indicate which domain of EF each item best exemplified. Items with poor agreement were eliminated from the final instrument. The construct validity for the BRIEF-2 was measured by comparing it to general measures of behavioral functioning since there were no existing ratings scales of EF (Gioia et al., 2015). 


\section{Procedure}

The researcher obtained permission from the local school district, FIU, and the school principal(s) to conduct this study. First, the study was submitted to FIU's IRB for approval. Next, the study was submitted to the public-school district's IRB committee. Once IRB approval was obtained from both institutions, the researcher met with school administrators, shared the IRB approval letters and explained the nature of the study. Once granted permission from the school administrators, the researcher began recruiting families and teachers for participation.

IRB approval forms. Approval to conduct this study was sought from FIU prior to the start of the study. The researcher followed the FIU protocols for recruiting, consenting, and assenting participants. Once IRB approval was obtained from FIU, a second IRB process was conducted for the public-school district.

Parent consent forms. Parents and/or the guardians for each participant were given a parental consent form. The form was approved by both IRB committees.

Participant selection. Once permission was obtained at these three levels (FIU, school district, and the parent/guardian), the researcher began recruiting participants. To recruit participants, the researcher distributed an informational flyer (approved by the FIU IRB) to select teachers and their students. Once teachers agreed to participate in the study, they distributed the flyer to potential participants' parents. The flyer contained the researchers' contact information to give parents the opportunity to learn more about the study or to indicate their willingness to have their child participate. The researcher recruited 95 participants for this study and secured 87 participants to obtain an effect size of .5. The eight that were not selected did not meet criteria to participate in the study. 
The .5 effect size generated in the power analysis is based on prior literature to determine the sample size. Consent meetings were held with parents who wanted to learn more about the study. Additionally, information from the study may be used or written in reports or presentations, but participants' identities will remain private and confidential.

Data collection procedures. For the present study, the researcher gathered data on the reading comprehension skills and EF abilities of 87 elementary school students ages 7.0-10.0 in the primary grades. The researcher reviewed the iReady diagnostic reading comprehension assessment of 87 students and selected 35 students with Tier 1 scores, 36 students with Tier 2 scores, and 16 students with Tier 3 scores. The researcher then administered a BRIEF-2 teacher questionnaire for each student to gather data on their EF abilities.

\section{Data Analysis}

The study implemented a descriptive correlational and predictive quantitative research design that looked at three contrasting groups: (a) grade level readers Tier 1, (b) at-risk reading comprehension deficits (RCD) Tier 2, and (c) poor RCD Tier 3. The study describes the status of the EF abilities of primary elementary school students at the different RTI tiers, as well as explore the relationship between EF and RCD.

After collecting the data, information was entered in to the statistical package for the social sciences program (SPSS) for analysis. Demographic information included (a) gender (boy or girl); (b) age (7.0-10.0); (c) ethnicity, and (d) RTI level. Quantitative results information included (a) iReady Comprehension - literary text scaled score; (b) 
iReady Vocabulary scaled score; (c) BRIEF-2 TRF T-scores (inhibit, shift, and working memory,).

Independent and dependent variables. The independent variables for the present study were: (a) EF abilities as provided by the BRIEF-2 teacher scores (three scales: Inhibit, Shift, and Working Memory) and (b) language skills as provided by the iReady vocabulary domain. The dependent variable under consideration for the present study was the RTI reading comprehension levels as provided by the iReady reading assessment reading comprehension, literary text domain.

Hypothesis 1. The first hypothesis was investigated using a multivariate analysis of variance (MANOVA) test. To address the null hypothesis, the researcher conducted a MANOVA test to ascertain if children in RTI reading Tier 1, Tier 2, and Tier 3 differ in EF skills as reported by their teachers on the BRIEF-2. The goal was to find significant differences between the groups to support further investigation of EF and RCD. Since the overall $F$ was significant, means were compared using the Scheffe Post-Hoc analysis ( $p<$ $.05)$ to determine differences between scores, since this is the most conservative test.

Hypothesis 2. The second hypothesis was tested using correlation tests. To address the second null hypothesis, the researcher conducted Pearson's correlational tests to determine associations in RTI Tier 1, Tier 2, and Tier 3 for reading scores, and the EF abilities of inhibition, working memory, and cognitive flexibility. In addition, the researcher ran an exploratory analysis using RTI groups combined and the EF abilities of inhibition, working memory, and cognitive flexibility (shifting). The goal was to find correlations among the variables to demonstrate a positive relationship between EF abilities and reading comprehension skills at each RTI tier. 
Hypothesis 3. The third hypothesis was tested using a multiple regression analysis. To address the third null hypothesis, the multiple regression analysis determined if the student's EF abilities of inhibition, memory, and cognitive flexibility predicted reading comprehension skills. In addition, the analysis provided specific information on which EF abilities inhibition, memory, or cognitive flexibility played a larger role in predicting reading comprehension. The researcher looked at two RTI groups, Tier 2 and Tier 3 (both with reading comprehension deficits (RCD) to determine patterns of EF deficits and to determine the predictability of RCD through EF screenings.

Hypothesis 4. Finally, to address the fourth hypothesis, the researcher conducted a hierarchical regression analysis. The hierarchical regression analysis determined if the student's EF abilities of inhibition, memory, and cognitive flexibility predicted reading comprehension skills when controlling for language (Cohen, Cohen, West \& Aiken, 2003). For this analysis, the researcher explored three EF abilities, inhibition, working memory, and cognitive flexibility, and through statistical analysis determined if they predicted Tier 2 and Tier $3 \mathrm{RCD}$. The researcher entered language skills as a covariate/ control factor in the first step of the regression equation, because language heavily influences reading comprehension (Garcia-Fernandez et al., 2012; Fry et al., 2009; Halloran, 2011; Sesma et al., 2009). The second step in hierarchical regression added the three EF ability scores. By using language as a control variable, the researcher was able to make a stronger conclusion about the predictive nature of EF on RCD because it allows for a larger EF contribution of variance in reading comprehension. 


\section{Summary}

The study investigated the relationship between EF and reading comprehension achievement. The researcher assessed reading achievement in comprehension, vocabulary and $\mathrm{EF}$ abilities via the administration of the iReady reading assessment and BRIEF-2 teacher rating scales for a group of elementary school students in the primary grades. The

data were analyzed using quantitative statistics to determine correlations between specific EF abilities and reading comprehension achievement. In addition, the relationship between EF abilities and reading comprehension skills were analyzed using hierarchical regression analyses, after controlling for language. 


\section{CHAPTER IV}

\section{Results}

This chapter details the results of a quantitative study that explored the relationships between reading comprehension skills and executive functioning as well as the predictability of executive functioning screenings for the early detection of reading comprehension deficits. Four hypotheses were tested for the study:

$\mathrm{H}_{01}$ : There is not a significant difference in EF, based on the BRIEF-2 TRF inhibition, cognitive flexibility, and working memory scores, between the grade level readers (Tier

1), at risk readers (Tier 2) and poor readers (Tier 3), based on iReady reading assessment (reading comprehension).

$\mathrm{H}_{1}$ : There is a significant difference in EF abilities between grade level readers (Tier 1), at risk readers (Tier 2), and poor readers (Tier 3).

$\mathrm{H}_{02}$ : Inhibition, cognitive flexibility, and working memory are specific EF abilities that do not correlate with reading comprehension skills.

$\mathrm{H}_{2}$ : There is a significant correlation between EF, based on the BRIEF-2 TRF inhibition, cognitive flexibility, and memory scores, and reading comprehension for grade level readers (Tier 1), at risk readers (Tier 2) and poor readers (Tier 3), based on iReady reading assessment (reading comprehension).

$\mathrm{H}_{03}$ : Inhibition, cognitive flexibility, and working memory are EF abilities that do not significantly predict reading comprehension. 
$\mathrm{H}_{3:}$ Inhibition, cognitive flexibility, and working memory EF abilities significantly predict reading comprehension in average (Tier 1), at risk readers (Tier 2) and poor readers (Tier 3), based on iReady reading assessment (reading comprehension).

$\mathrm{H}_{04}$ : Inhibition, cognitive flexibility, and working memory are EF abilities that do not predict reading comprehension after controlling for language skills.

$\mathrm{H}_{4}$ : Inhibition, cognitive flexibility, and working memory EF abilities predict reading comprehension, after controlling for language, based on iReady reading assessment (vocabulary) in grade level (Tier 1), at risk readers (Tier 2) and poor readers (Tier 3).

The independent variables for this study were the EF abilities of inhibition, cognitive flexibility (shifting), and working memory as well as the non-EF ability of language skills. The dependent variable was reading comprehension. The researcher collected reading comprehension skills and language skills data using the iReady assessment. Data on executive functioning abilities were collected using the Behavioral Rating Inventory of Executive Functioning, second edition (BRIEF-2).

\section{Description of the Participants}

The participants for this study included 87 students between the ages of seven and 10 who attended a public school in a large urban school district in the south-east US. The participants were in grades one through three and received reading instruction via the response to intervention framework. There were 27 first graders $(\mathrm{N}=27), 29$ second graders $(\mathrm{N}=29)$ and 31 third graders $(\mathrm{N}=31)$ in the study. The students who participated in the study were classified as $40 \%(\mathrm{~N}=35)$ in Tier $1,41 \%(\mathrm{~N}=36)$ as Tier 2 , and $16 \%$ $(\mathrm{N}=16)$ as Tier 3 . The gender of the sample was $52 \%$ male $(\mathrm{N}=45)$ and $48 \%$ female 
$(\mathrm{N}=42)$. Demographic data retrieved from the public-school district's student records revealed that $87 \%$ of the sample identified as Hispanic, $3 \%$ of the sample identified as White, $8 \%$ identified as Black, and 2\% identified as Asian.

\section{Discussion and Data Analysis}

\section{Hypothesis statement 1- There is a significant difference in EF abilities between grade level readers (Tier 1), at risk readers (Tier 2), and poor readers (Tier 3).}

A multivariate analysis of variance (MANOVA) test was used to explore the relationship between RTI tiers 1, 2, and 3 and the BRIEF-2 inhibit, shift, and working memory scores. The MANOVA test provided a comparison between the dependent variables (inhibition, shifting, and working memory) and the independent variable (reading comprehension skills divided into three RTI groups tiers 1, 2 and 3). The MANOVA analysis revealed a significant effect for RTI reading comprehension Tiers on shift scores, $F(2,85)=7.545, p=.001$. Results also demonstrated a significant effect of RTI reading comprehension tiers on working memory scores, $F(2,85)=11.857, p<.001$. The MANOVA analysis demonstrated no significant effect of RTI reading comprehension tiers on inhibition scores, $F(2,85)=1.066, p>.05$. Table three demonstrates the $F$ values and significant values for each EF ability. 
Table 3

Correlations by EF Abilities

\begin{tabular}{lll}
\hline EF ability & $F$ value & Sig value \\
Inhibition & 1.066 & .349 \\
Shifting & 7.545 & .001 \\
Working Memory & 11.857 & .000 \\
\hline${ }^{*} p>.05$ & &
\end{tabular}

The Sheffee post hoc test was used to further investigate the relationship between each EF ability of inhibition, shifting, and working memory and the RTI reading comprehension tiers. The MANOVA test allowed for the comparison of the multiple dependent variables of inhibition, shifting, and working memory against the independent variables of the three groups (RTI tiers 1,2, and 3). The post hoc analysis indicated differences in EF shift scores between children in RTI reading comprehension Tier 1 and Tier 2, with Tier 2 children scoring higher (i.e., greater deficit) on shift than RTI Tier 1 children ( $p=.011)$. Post hoc analysis demonstrated a significant difference between students in RTI Tier 1 and Tier 3, with RTI Tier 3 students scoring higher (i.e., greater deficit) on shifting compared to RTI Tier 1 students $(p=.004)$. There were no significant differences in shifting scores between RTI Tier 2 and RTI Tier 3 students $(p>.05)$. The post hoc analysis also indicated significant differences in EF working memory scores between RTI reading comprehension Tier 1 and RTI Tier 2, with Tier 2 children scoring higher (i.e., greater deficit) on working memory than the Tier 1 students $(p=.008)$. The post hoc analysis also demonstrated a significant difference between children in RTI Tier 1 and RTI Tier 3, with RTI Tier 3 students scoring higher on working memory when 
compared to the RTI Tier 1 children $(p<.001)$. There was no significant difference in working memory scores between RTI Tier 2 and RTI Tier 3 students $(p>.05)$. Overall, regardless of the tier level, students did not differ in their EF inhibitory abilities.

However, Tier 1 children scored well on shifting and working memory (i.e., where lower scores indicate better functioning). Tier 2 and Tier 3 students demonstrated deficits in shifting and working memory. Table 4 displays means and standard deviations on EF abilities across RTI tiers.

Table 4

BRIEF-2 Means and Standard Deviations by RTI Tier

\begin{tabular}{llcc}
\hline EF Ability & RTI Tier & Mean & SD \\
Inhibition & Tier 1 & 52.46 & 15.40 \\
& Tier 2 & 57.75 & 16.02 \\
& Tier 3 & 56.37 & 14.87 \\
& Total & 55.37 & 15.59 \\
Shift & Tier 1 & 46.09 & 12.68 \\
& Tier 2 & 56.17 & 15.47 \\
& Tier 3 & 60.25 & 11.99 \\
& Total & 52.86 & 14.813 \\
& Tier 1 & 50.31 & 10.71 \\
& Tier 2 & 61.00 & 17.28 \\
& Tier 3 & 70.12 & 15.81 \\
& Total & 58.38 & \\
\hline
\end{tabular}




\section{Hypothesis statement 2 -There is a significant correlation between EF, based}

on the BRIEF-2 TRF inhibition, cognitive flexibility, and memory scores, and reading comprehension for grade level readers (Tier 1), at risk readers (Tier

2) and poor readers (Tier 3), based on iReady reading assessment (reading comprehension).

Pearson's correlation tests were used to explore whether significant correlations were identified between reading comprehension skills and EF scores for inhibition, shifting and working memory. Analyses were conducted separately by RTI tiers. There were no significant differences identified between inhibit scores and reading comprehension scores for any RTI Tiers (each $p>.05$ ). No significant differences were identified between shift scores and reading comprehension for any RTI Tier (each $p>$ .05). Additionally, no significant differences were identified between working memory scores and reading comprehension for any RTI tier (each $p>.05$ ). Exploratory analysis utilized the full sample (i.e., not grouped by RTI tier) to boost statistical power. Results indicated that inhibit scores were not significantly correlated with reading comprehension scores across the full sample $(p>.05)$. However, EF shifting scores were significantly negatively correlated with reading comprehension scores across the full sample $(r=-$ $.358, \mathrm{p}=.001)$. Additionally, EF working memory scores were also significantly negatively correlated with reading comprehension scores across the full sample $(r=$ $.432, \mathrm{p}<.001)$. This result means that when students demonstrated high levels of deficits in the EF ability of shifting, they demonstrated low reading comprehension skills. In addition, when student demonstrated high levels of deficits in the EF ability of working memory, they also demonstrated lower reading comprehension skills. Table 5 
demonstrates all the Pearson correlation analysis separated by RTI tiers and using the full sample.

Table 5

BRIEF-2 Correlations with Reading Comprehension

\begin{tabular}{lll}
\hline EF Ability & RTI Tier or Full Sample & $r$ \\
\hline Inhibition & Tier 1 & -.102 \\
& Tier 2 & .014 \\
& Tier 3 & -.063 \\
& Full Sample & -.129 \\
Shifting & Tier 1 & -.018 \\
& Tier 2 & -.151 \\
& Tier 3 & -.195 \\
Full Sample & $-.358^{*}$ \\
Tier 1 & .119 \\
& Tier 2 & -.190 \\
& Tier 3 & -.434 \\
& Full Sample & $-.432^{*}$ \\
\hline
\end{tabular}

$* p<.001$

Hypothesis statement 3- Inhibition, cognitive flexibility, and working memory EF abilities significantly predict reading comprehension in average (Tier 1), at risk readers (Tier 2) and poor readers (Tier 3), based on iReady reading assessment (reading comprehension). 
A multiple regression analysis was conducted to determine whether reading comprehension skills could be predicted based on the EF abilities of shifting, inhibition and working memory. The multiple regression model included inhibition, shifting, and working memory scores as the independent variables and reading comprehension scores as the dependent variable. The results indicated that the overall model found a significant effect between EF abilities and reading comprehension, $F(3,48)=4.196, p=.01, R^{2}=$ .21. More specifically, working memory was a significant individual predictor of reading comprehension with participants reading comprehension scores decreasing 1.870 points for every one-point increase in working memory scores $(p=.009)$. Inhibition and shift scores were not significant individual predictors of reading comprehension in the regression model $(p>.05)$. Overall, working memory was a significant predictor of reading comprehension in children labeled as being at risk for reading comprehension difficulties. These results confirm that the BRIEF-2 teacher rating scale of working memory is a good predictor of reading comprehension skills. Table 6 displays the individual unstandardized regression coefficients, standardized regression coefficients, and standard error for the multiple regression model.

Table 6

Multiple Regression Analysis of EF Ability Scores and Reading Comprehension Scores

\begin{tabular}{lccc}
\hline EF Ability & B & SE B & $\beta$ \\
\hline Inhibition & .940 & .502 & .325 \\
Shift & .503 & .821 & .162 \\
Working Memory & -1.87 & .682 & $-.684^{*}$ \\
\hline $\mathrm{R}^{2}=.21, * p<.05$ & & &
\end{tabular}




\section{Hypothesis statement 4 - Inhibition, cognitive flexibility, and working}

memory EF abilities predict reading comprehension, after controlling for language, based on iReady reading assessment (vocabulary) in grade level (Tier 1), at risk readers (Tier 2) and poor readers (Tier 3).

A hierarchical regression analysis was conducted to determine the predictability of reading comprehension skills through EF screenings after controlling for language abilities. The researcher looked at two RTI groups with reading comprehension deficits (RCD): Tier 2 and Tier 3. The hierarchical regression model included the student's vocabulary scores as a measure of language abilities and as an independent variable at step 1, and then inhibition, shifting, and working memory scores as independent variables at step 2. The student's reading comprehension score was the dependent variable. The results for step 1 of the hierarchical regression model indicate that the overall model was significant and vocabulary has an effect on reading comprehension, $F(1,51)=48.135, p<$ $.01, R^{2}=.49$. The vocabulary score was a significant individual predictor of reading comprehension, as each student's reading comprehension scores increased by .620 points for every one-point increase in their vocabulary score $(p<.001)$. Next, inhibition, shift, and working memory scores were added at step 2 of the hierarchical model. The overall model was significant, indicating that there is an effect of vocabulary and EF abilities on reading comprehension, $F(4,47)=12.303, p<.01, R^{2}=.51$. Adding the inhibit, shift, and working memory scores to the model did account for a significant increase in the variance explained by the model, $R^{2}$ change $=.021, p>.05$. Results for the individual predictor variables indicate that the vocabulary score is still a significant predictor of reading comprehension at step $2(p=.003)$. Inhibit, shift, and working memory scores 
were not significant predictors of reading comprehension when controlling for vocabulary scores (each $p>.05$ ). Table 7 shows the individual unstandardized regression coefficients, standardized regression coefficients, and standard error at each step of the hierarchical regression model.

Table 7

Hierarchical Regression Analysis

\begin{tabular}{lllll}
\hline Hierarchical Step & Predictor & B & SE B & $\beta$ \\
\hline Step 1 & Vocabulary & .630 & .091 & $.700^{*}$ \\
Step 2 & Vocabulary & .592 & .110 & $.658^{*}$ \\
& Inhibition & .184 & .423 & .064 \\
& Shift & .710 & .653 & .229 \\
& Working Memory & -.764 & .578 & -.279 \\
& & & & \\
\hline
\end{tabular}

Step $1 R^{2}=.49$ Step $2 R^{2}=.51 * p<.05$

\section{Summary}

This study was conducted to learn about the relationships between the three EF abilities of inhibition, shifting, and working memory and reading comprehension skills. Also, the predictive ability of EF screenings for the early detection of reading comprehension deficits were explored. The results indicated that there are correlations between EF shifting and EF working memory abilities and reading comprehension skills. Students who demonstrated deficits in shifting and working memory also demonstrated lower scores in reading comprehension. The results also indicated that EF abilities showed a significant effect on reading comprehension. More specifically the EF ability of working memory was a significant predictor of reading comprehension skills. When 
controlling for language, the vocabulary scores proved to be a better predictor of reading comprehension deficits than $\mathrm{EF}$ abilities. 


\section{CHAPTER V}

\section{Discussion}

Chapter five provides a discussion of the results of this study. This study investigated the patterns of EF strengths and weaknesses in students receiving reading comprehension interventions by means of the RTI three tier framework. The results demonstrate which specific EF strengths and weaknesses in inhibition, shifting, and working memory are found in students at the Tier 1, Tier 2 and Tier 3 reading level. In addition, predictive capabilities resulting from EF abilities on reading comprehension skills were investigated.

\section{Findings Related to the First Hypothesis Statement}

Hypothesis statement 1- There is a significant difference in EF abilities between grade level readers (Tier 1), at risk readers (Tier 2), and poor readers (Tier 3$)$.

This statement investigated whether there was a significant difference in the students' EF abilities of inhibition, shifting (cognitive flexibility), or working memory depending on their reading level within the three tier RTI framework. Results indicated that there was a significant difference in the shifting (cognitive flexibility) and the working memory scales when comparing Tier 1 students to the Tier 2 and 3 students. Students in Tier 1 had lower scores in shifting and working memory indicating no weakness in these areas. Students in Tier 2 and 3 combined had higher scores in shifting and working memory indicating weaknesses in these two EF abilities.

These findings support the theoretical framework presented in the literature review of this paper. EF abilities are found in the prefrontal cortex (PFC) and are 
responsible for connecting, coordinating and organizing neuro-transmitted information (Cartwright, 2012; Miyake et al., 2000; Zelazo et al., 2016). Students use cognition to implement EF abilities (i.e., cognitive flexibility, working memory and inhibition) to conduct analysis of information, problem solve and accomplish goals (Christopher et al., 2012; Cunningham \& Zelazo, 2007; Kim et al., 2018; Miyake et al., 2000; Zelazo, 2015; Zelazo et al., 2016). Further, individuals with poor EF abilities struggle to develop skills that allow for academic achievement (Cunningham \& Zelazo, 2007; Zelazo, 2015; Zelazo et al., 2016). The results from this study further demonstrate that there are differences in EF abilities between high (Tier 1), medium (Tier 2), and low (Tier 3) performing students in reading. Moreover, children who are struggling in reading and reading comprehension experience difficulties in EF, particularly cognitive flexibility and working memory (Cartwright, 2012; Jacob \& Parkinson, 2015). In addition, EF abilities are necessary for success in reading comprehension (Carlson et al., 2013; Garon et al., 2008; Hughes, 2011; Jacques \& Marcovitch, 2010; Meuwissen \& Zelazo, 2014). These results provide support for theories that highlight differences in EF abilities for average readers and lower performing readers. The results from the current study indicate that students at Tier 2 and 3 of RTI with reading comprehension deficits who are working below grade level are demonstrating weaknesses in shifting (cognitive flexibility) and working memory. This means that students who are tagged as Tier 2 and Tier 3 have EF weaknesses. It is possible that their difficulty with memory is affecting their ability to remember the meaning of words, the content that they have read, and access prior knowledge when reading passages. In addition, the Tier 2 and Tier 3 students' difficulty with cognitive flexibility makes it difficult for them to shift between the complex strategies needed to 
complete reading tasks and comprehend. The students in Tier 1 showed no weakness in executive functioning, meaning that they have the EF tools necessary to read and comprehend on grade level.

\section{Findings Related to the Second Hypothesis Statement}

There is a significant correlation between EF, based on the BRIEF-2 TRF inhibition, cognitive flexibility, and memory scores, and reading comprehension for grade level readers (Tier 1), at risk readers (Tier 2) and poor readers (Tier 3), based on iReady reading assessment (reading comprehension).

This statement investigated whether there was a significant correlational relationship between the EF abilities of shifting (cognitive flexibility), inhibition and working memory and reading comprehension skills. The results indicated that significant correlations were found between shifting (cognitive flexibility) and reading comprehension. Students who scored as having deficits in shifting demonstrated lower reading comprehension scores. The results indicated that significant correlations were found between working memory and reading comprehension. Students who scored as having deficits in working memory demonstrated lower reading comprehension scores. The results indicated that there were no significant correlations found between inhibition and reading comprehension. Students who scored as having deficits in inhibition demonstrated higher reading comprehension scores.

Previous literature and research supports these findings as students with reading comprehension deficits have demonstrated difficulties in cognitive flexibility and working memory (Cartwright, 2012; Cartwright et al., 2016; Christopher et al., 2012; 
Dahlin, 2011; Garcia-Madruga et al., 2013; Jacob \& Parkinson, 2015; Sesma et al., 2009). In addition, EF and reading comprehension hold a strong relationship because EF has little to do with rote memorizing or learning facts (i.e., vocabulary and spelling words) and more to do with reasoning, problem solving and using the knowledge acquired from rote memory to make inferences and solve problems (Miyake et al., 2000; Zelazo, 2016). Reading comprehension is a highly demanding task that requires coordination of various EF abilities (Blair \& Raver, 2015; Cartwright et al., 2016; Vukovic et al., 2014; Zelazo, 2016). The results from this study provide clear support for the theories that highlight the relationship between cognitive flexibility and working memory abilities and reading comprehension skills for academic success. Cognitive flexibility allows for a more flexible reading style that impacts the ability to discover the semantic relationships between words, infer meaning from context, grow vocabulary, and make inferences from the text from prior knowledge (Cartwright, 2012; Cartwright et al., 2016; Jacob \& Parkinson, 2015). It also aids in the ability to manage the phonological and semantic processes of reading (Cartwright, 2012; Cartwright et al., 2016; Jacob \& Parkinson, 2015). Working memory allows for the retention of information as well as the ability to manipulate it to solve problems (Christopher et al., 2012; Dahlin 2011; GarciaMadruga et al., 2013; Miyake et al., 2000).

The results stemming from the inhibition scale do not support those found in the research. Previous literature and research demonstrate that inhibition and attention play a significant role in reading comprehension as they allow for the student to control and regulate where he or she places attention (Espinet et al., 2013; Keiffer et al., 2013; Locascio et al., 2010; Miyake et al., 2000; Zelazo, 2014). Inhibition also refers to the 
ability to suppress or remove outdated information and ignore irrelevant stimuli to maintain focus on a goal. Studies found that inhibition did have an important role in student's success in reading comprehension (Espinet et al., 2013; Keiffer et al., 2013; Locascio et al., 2010; Miyake et al., 2000; Zelazo, 2014). It is surprising that the finding from this study regarding inhibition are contradictory to that found in the research. It is unlikely that the more difficulty a student has focusing and blocking out distractions the better their reading comprehension scores will be. It is possible that in this particular sample the students who scored well in reading comprehension have an underlying focusing issue. In addition, their reading comprehension scores may not have been affected due to the nature of the iReady test, because it is computerized and engaging. The test provides visual graphics and stimuli. In addition, the program helps students track while they are reading. Also, the reading test is able to track if students are fatigued and provide breaks in the form of a quick computer game.

\section{Findings Related to the Third Hypothesis Statement}

Inhibition, cognitive flexibility, and working memory EF abilities significantly predict reading comprehension in average (Tier 1), at risk readers (Tier 2) and poor readers (Tier 3), based on iReady reading assessment (reading comprehension).

This statement investigated the predictive abilities of EF shifting (cognitive flexibility), inhibition, and working memory on reading comprehension skills. The researcher looked at two RTI groups, Tier 2 and Tier 3 (both with reading comprehension deficits (RCD) to determine the predictability of RCD through EF screenings. The results indicated that working memory was the only significant predictor of reading 
comprehension scores. As students scored higher (indicating a greater deficit) on the BRIEF-2 working memory scale they scored lower in reading comprehension on iReady.

The review of the literature supports that working memory has a significant impact on reading comprehension skills (Cartwright, 2012; Denton, 2016; Gilbert et al., 2012; Spencer et al., 2014). The predictability of reading comprehension deficits using working memory is important because it allows for the early identification and implementation of effective interventions. Research shows that students are struggling with reading deficits in the early elementary years, however others do not start showing difficulties until it is time to read fluently or comprehend text (Cartwright, 2012; Denton, 2016; Gilbert et al., 2012; Spencer et al., 2014). Other studies found that nearly half of the students identified with late emerging reading difficulties have issues with comprehension and have undetected difficulties that may have been present at an earlier age (Al Otaiba et al., 2014; Catts et al., 2012; Christopher et al., 2012; Nation, et al., 2010; O'Connor et al., 2013). This is because all areas of reading pace a heavy demand on EF (Cartwright, 2012; Christopher et al., 2012; Cutting et al., 2009; Fuchs et al., 2015; Keiffer et al., 2012; Miyake et al., 2000; Sesma et al., 2009). The results found in this study support the use for EF screenings as a multimodal complete screening procedure when making decisions how to help struggling readers as previous literature demonstrates connections between EF and early schooling success (Blair \& Razza, 2007; Kim et al., 2018; Welsh et al., 2010).

Only the working memory scale served as a predictor of RCD. While the cognitive flexibility/ shifting scale showed correlations, the relationship was not strong enough to be a predictor as it has been in other studies. This may be due to the nature of 
the EF assessment. Being a rating scale makes it more of a rating of observed behaviors. It is possible that the cognitive flexibility/ shifting ability is more difficult to measure through observation. In addition, inhibition showed no relationship to RCD. This may be due to the nature of the reading comprehension iReady test. It is possible that the computerized nature of the test assisted students who are normally easily distracted in class. Also, the test provides breaks throughout where children are able to play a game.

\section{Findings Related to the Fourth Hypothesis Statement}

Inhibition, cognitive flexibility, and working memory EF abilities predict reading comprehension, after controlling for language, based on iReady reading assessment (vocabulary) in grade level (Tier 1), at risk readers (Tier

\section{2) and poor readers (Tier 3).}

This statement investigated the predictive abilities of EF shifting (cognitive flexibility), inhibition, and working memory on reading comprehension skills while controlling for language abilities. The researcher looked at two RTI groups, Tier 2 and Tier 3, both with reading comprehension deficits. Language was added to strengthen the claim that $\mathrm{EF}$ is predictive of RCD. The results indicated that language abilities are a strong predictor of RCD. As students scored lower in language abilities, they also scored lower on reading comprehension skills. When the EF abilities of inhibition, shifting (cognitive flexibility), and working memory were added into the regression, there was a significant increase in the variance; however, they were not good individual predictors of reading comprehension deficits. Language (as measured by vocabulary scores) was the only individual predictive measure of RCD. 
A review of the literature indicates that language abilities are an important part of reading comprehension success (Denton, 2012; Gilbert et al., 2012; O'Connor et al., 2013; Spencer et al., 2014). Much of the research shows that difficulties in in vocabulary development makes it difficult for students to understand word meaning and access prior knowledge when reading and comprehending text (Garcia-Fernandez et al., 2012;

Halloran, 2011; Kibby et al., 2004; Sesma et al., 2009). In addition, educators are seeing much success with the implementation of many RTI Tier 2 and Tier 3 interventions that focus mostly on linguistics, phonics, and vocabulary development (Garcia-Fernandez et al., 2012; Goldstein et al., 2014). This success with RTI Tier 2 and 3 interventions has helped with the decrease in the overall representation of students with RCD in special education, because students with RCD are showing improvement without the need of a special education setting. Reading acquisition begins with the learning of letter names and sounds and moves on to phonemic awareness, decoding, fluency and comprehension (Denton, 2012; Gilbert et al., 2012; Spencer et al., 2014). However, EF does play a role in language acquisition and oral language comprehension (Blair \& Razza, 2007; Kim et al., 2018; Welsh et al., 2010). While traditional linguistic RTI reading interventions are improving many struggling readers skills, data do indicate that $15 \%$ of students in RTI Tier 2 and 3 are continuing to struggle due to unidentified learning issues (Flanagan et al., 2006; Fuchs et al., 2010; Garcia et al., 2012; Gilbert et al., 2012; Kavale \& Spaulding, 2008; NCLB, 2014; O'Connor et al., 2013). While the results indicate that language is the only individual predictor of RCD, inhibition, shifting (cognitive flexibility), and working memory EF abilities provided a significant increase in variance between scores. These results make a case for including EF as part of a multimodal screening or assessment 
process when making decisions on RTI placement and interventions. Previous studies have indicated late identification of students with RCD, when using single mode RTI screenings (Cartwright, 2012; Christopher et al., 2012; Fuchs et al., 2015; O'Connor et al., 2013; Spencer et al., 2014). Also, previous studies have demonstrated less progress when students are administered a general reading intervention over an individualized one that results from proper screenings (Cartwright, 2012; Christopher et al., 2012; Fuchs et al., 2015; O’Connor et al., 2013; Spencer et al., 2014). Language abilities allow students to acquire vocabulary, understand syntax, receptive and expressive language (Denton, 2012; Gilbert et al., 2012; Spencer et al., 2014). The results of this study support the notion that language abilities are essential to the successful acquisition of reading skills and comprehension skills. These results also support the vast success of RTI programs being implemented in schools as many of these programs implement language-based interventions. However, the current study's results also support the notion that the EF abilities of inhibition, shifting and working memory improved the reading comprehension scores.

\section{Implications}

The results of this study have implications for students struggling with reading comprehension who are being taught using an RTI three tier framework. Reading comprehension is a highly demanding task that requires sustained attention, simultaneous processing of information (cognitive flexibility) and working memory (Cartwright et al., 2016; Dahlin, 2011; Christopher et al., 2012; Garcia-Madruga., 2013; Guajardo \& Cartwright, 2016; Kim et al., 2018). In addition, EF plays a role in language acquisition and oral language comprehension which are important skills for reading comprehension 
(Blair \& Razza, 2007; Kim et al., 2018; Welsh et al., 2010). Students with RCD lack various developmental abilities and skill sets, such as language, cognitive, and EF abilities. The results of this study support the concept of incorporating EF screenings when making decisions on students who are struggling with reading comprehension to help individualize the RTI framework.

The results of this study indicate that adding an EF screening tool that specifically measures cognitive flexibility/ shifting and working memory can provide valuable information when making decisions on RTI placement and intervention design. Reading comprehension deficits are among the most prevalent academic areas where students struggles (Fry et al., 2009; Sesma et al., 2009). Researchers have discovered a lack of individualization in the evaluations, screenings and interventions used to help students (Kavale \& Spaulding, 2008). The current study found significant correlations between the EF abilities of cognitive flexibility and working memory and reading comprehension skills. In addition, working memory proved to be a significant predictor of RCD. Last, the results showed that language abilities were the strongest individual predictor of RCD, however adding EF abilities added a significant variance to the scores. Supporting the important effect $\mathrm{EF}$ has on reading comprehension success.

The variance provided by the EF abilities could account for those students who are not responding to traditional non-individualized models of RTI. Research shows that students with RCD have poor EF abilities and are less efficient in the usage of reading strategies, have poor self-regulation, and have difficulty coordinating and integrating information to effectively process written material (Garcia-Fernandez et al., 2012; Halloran, 2011; Sesma et al., 2009). In addition, the predictability of working memory on 
RCD can help with early identification, which allows for better interventions preventing students from falling further behind (Gilbert et al., 2012; Spencer et al., 2014). Current research supports the use of EF interventions for improving RCD due to the trainability of the construct (Cunningham \& Zelazo, 2007; Zelazo et al., 2016; Zelazo 2015). The results from each student's EF screenings can provide specific information about their EF deficits to inform which interventions to use. This further individualizes the RTI process and supports the frameworks ideology that if a student is not responding to the intervention educators should be collecting data and trying other interventions.

The results from this study support the correlational relationship between cognitive flexibility and working memory on reading comprehension success. Current research shows that cognitive flexibility has strong correlations to reading achievement. Cognitive flexibility refers to a student's ability to analyze information in multiple ways, such as considering multiple perspectives on an issue or multiple ways to solve a problem (Carlson et al., 2013; Christopher et al., 2012; Garon et al., 2008; Hughes, 2011; Jacquies \& Marcovitch, 2010; Kim et al., 2018; Meuwissen \& Zelazo, 2014; Miyake et al., 2000). Students' inflexible reading styles impact their ability to discover semantic relationships between words, infer meaning from context, grow their vocabulary over time, and make inferences from prior text (Cartwright et al., 2016). Current studies support the use of EF interventions as effective in improving reading comprehension skills (Cartwright, 2016; Guajardo \& Cartwright, 2016; Karbach \& Kray, 2009). Interventions that target cognitive flexibility and working memory allow student to improve and develop the tools necessary to carry out the complex process of comprehending text. In addition, knowledge on each 
student's EF strengths and weaknesses help guide educators in selecting which strategies and interventions are most appropriate.

Current research supports the results of this study and shows that working memory has strong correlations to reading comprehension. Working memory refers to the ability to retain information as well as manipulate or updating it to solve problems (Carlson et al., 2013; Garon et al., 2008; Hughes, 2011; Jacques \& Marcovitch, 2010; Meuwissen \& Zelazo, 2014; Mikaye et al., 2000). It includes the integration of various concepts and ideas to comprehend text and answer questions about text (Carlson et al., 2013; Garon et al., 2008; Hughes, 2011; Jacques \& Marcovitch, 2010; Meuwissen \& Zelazo, 2014; Mikaye et al., 2000). Current studies also supported the implementation of working memory interventions as effective methods for improving reading comprehension skills (Christopher et al., 2012; Dahlin, 2011; Garcia-Madruga et al., 2013).

The results from the study support the predictive relationship of working memory and reading comprehension deficits. These results support the use of EF screeners, particularly the working memory piece, for early identification and intervention planning. These EF screeners provide valuable insights into the students EF abilities and can be administered during the RTI process to better individualize interventions (Garcia et al., 2012; Gilbert et al., 2010; Kavale \& Spaulding, 2008; O’Connor et al., 2013). While most RTI frameworks do not consider a student's EF abilities, interventions that focus on improving reading-related EF abilities have proven successful due to the trainable and malleable nature of EF (Cartwright, 2016). 
The results of this study also support the predictive relationship of language abilities and reading comprehension. These predictive abilities proved to be stronger individually than any of the EF abilities measured. Language abilities are important for reading success as language allows student to build vocabulary and understand context. It is also the reason that traditional interventions that provide additional support through RTI have helped so many struggling readers. That said, there is still a case to be made regarding the correlation between the EF abilities of cognitive shifting and working memory on reading comprehension. Current research demonstrates that interventions that focus on building EF abilities should be implemented in addition to interventions that work on word deciding, reading fluency, and comprehension (Bledsoe et al., 2010; Garcia-Fernandez et al., 2012; Halloran, 2011; Sesma et al., 2009). There are various studies that show positive correlations and positive outcomes between EF and RCD (Ezpeleta et al., 2015; Garcia-Fernandez et al., 2012; Menezes et al., 2015). In addition, there is much research to support the implementation of comprehensive screenings and individualized interventions for students with RCD (Gilbert et al., 2012; Spencer et al., 2014).

\section{Limitations}

There are several limitations to this study that must be considered when interpreting its results and implications. The study was conducted with elementary school students in the primary grades. It is unknown if similar results would have been found with students of different ages, particularly as reading comprehension skills have a heavier weight on academic success in the older elementary grades (fourth and fifth 
grades). In addition, students with RCD were explored; it would be interesting to see if similar results would have been found with students struggling in writing or math.

Another limitation of this study was the small sample size, particularly of the Tier 3 students. Having a larger sample with more students in Tier 3 demonstrating significant RCD would have allowed for more statistical power. Replicating this study with a focus on including a larger number of students with significant Tier 3 level RCD is recommended. Additionally, a large percentage of the population of this study are bilingual and Hispanic in ethnicity. Future research should include students with varied racial representation and socio-economic levels. A more varied population would allow for more generalizability of the findings.

An additional limitation is that the quantification of the EF abilities was limited to one measure (the BRIEF-2). Although this is common practice in EF assessment, many studies implement various measures (Chan et al., 2008; Gioia et alk., 2001; Isquith et al., 2005; Lamberts et al., 2010; Nilsen et al., 2017; Toplack et al., 2013; Zelazo et al., 2016). Also, the findings might have been limited by the tool used in the present study (the BRIEF-2). The BRIEF-2 measures EF through guided observations of behaviors; it would be interesting to repeat this study using a performance-based measure of EF, such as the NEPSY, the WISC-V integrated, or the Delis Kaplan. Comparing these results could help further validate the case for using EF rating scales as screeners for RTI. While similar studies have been conducted using guided behavior measures, many included in the literature review used performance-based measures of EF (Christopher et al., 2012; Garcia-Madruga et al., 2013; Kim et al., 2018; Miyake et al., 2000). 


\section{Suggestions for Future Research}

This study examined the potential correlational and predictive relationship between cognitive flexibility, inhibition, and working memory EF abilities on reading comprehension skills. These results provide data that can support the use of EF assessment as a screening tool to further individualize the types of RTI interventions provided to students who are struggling with RCD. The results have extended research in this area supporting the notion that the EF abilities of cognitive flexibility and working memory have a significant correlational relationship with RCD. In addition, the results indicate that working memory has a significant predictive ability for RCD. Last while EF abilities demonstrated significant variance with RCD, language and vocabulary abilities were the strongest predictors of RCD. There are still ways that the potential of EF assessment on struggling students can be further explored. The following are suggestions for future research:

1. A replication of this study using a larger sample size, including more students with more severe RCD.

2. A replication of this study using a performance-based measure of cognitive flexibility and working memory EF abilities.

3. A replication of this study using students in older elementary students in fourth and fifth grades.

4. An exploration of the relationship of the EF abilities of students struggling in other academic areas, such as math or writing.

5. An exploration of the relationship of the EF abilities of students struggling with vocabulary development, as much of the research demonstrates connections 
between EF and language development (Blaie \& Razza, 2007; Cartwright, 2012;

Kim et al., 2018; Welsh et al., 2010).

\section{Summary}

The results of this study suggest that EF screenings can be used to acquire specific data regarding a student's learning strengths and weaknesses when making decision for RTI placement and interventions. The researcher gathered data on reading comprehension skills, language abilities and EF abilities for 87 students attending a large urban publicschool district in the south-east US. The reading comprehension was assessed using the Spring 2018 iReady reading comprehension assessment. The language abilities were assessed using the Spring 2018 iReady vocabulary assessment. The EF abilities were assessed using the inhibition, shifting and working memory scales from the BRIEF-2 behavioral rating scale. The results showed that there are correlational relationships between working memory EF abilities and cognitive flexibility EF abilities on reading comprehension. In addition, the EF ability of working memory was found to be a strong independent predictor of reading comprehension skills. Last, language abilities were found to be the strongest independent predictor of reading comprehension skills.

The findings of from this study provide new information on how to improve the screening process for RTI. The BRIEF-2 can be used as a screener that guides RTI interventions that focus on strengthening and developing the working memory and cognitive flexibility abilities of students struggling with reading comprehension. In addition, results that show extreme dysfunction can alert educators to the need for a more complex evaluation. These results also contribute to the literature that supports the relationship between EF and reading comprehension. 


\section{REFERENCES}

Al Otaiba, S., Kim, Y. S., Wanzek, J., Petscher, Y., \& Wagner, R. K. (2014). Long-term effects of first-grade multitier intervention. Journal of research on educational effectiveness, 7(3), 250-267. https://doi.org/10.1080/19345747.2014.906692

Alloway, T. P., Gathercole, S. E., Adams, A. M., Willis, C., Eaglen, R., \& Lamont, E. (2005). Working memory and phonological awareness as predictors of progress towards early learning goals at school entry. British Journal of Developmental Psychology, 23(3), 417-426. https://doi.org/10.1348/026151005X26804

American Psychiatric Association. (2013). Diagnostic and statistical manual of mental disorders (5th ed.). Arlington, VA: Author.2013-14907-000

Anderson, V., Jacobs, R., \& Anderson, P. J. (Eds.). (2010). Executive functions and the frontal lobes: A lifespan perspective. Psychology Press.

Barnett, W.S., Jung, K., Yarosz, D.J., Thomas, J., Hornbeck, A., Stechuk, R., and Burns, S. (2008). Educational effects of the tools of the mind curriculum: A randomized trial. Early Childhood Research Quarterly, 23(3): 299-313. https://doi.org/10.1016/j.ecresq.2008.03.001

Blair, C., and Raver, C.C. (2014). Closing the Achievement Gap Through Modification of Neurocognitive and Neuroendocrine Function: Results from a Cluster Randomized Controlled Trial of an Innovative Approach to the Education of Children in Kindergarten. PLoS ONE, 9(11): e112393. doi: 10.1371/journal.pone.0112393

Benson, P., \& Voller, P. (2014). Autonomy and independence in language learning. Routledge.

Blair, C., \& Razza, R. P. (2007). Relating effortful control, executive function, and false belief understanding to emerging math and literacy ability in kindergarten. Child development, 78(2), 647-663. https://doi.org/10.1111/j.1467-8624.2007.01019.x

Booth, J. N., Boyle, J. M., \& Kelly, S. W. (2010). Do tasks make a difference? Accounting for heterogeneity of performance of children with reading difficulties on tasks of executive function: Findings from a meta-analysis. British Journal of Developmental Psychology, 28(1), 133-176. https://doi.org/10.1348/026151009X485432 
Bull, R., Espy, K. A., \& Wiebe, S. A. (2008). Short-term memory, working memory, and executive functioning in preschoolers: Longitudinal predictors of mathematical achievement at age 7 years. Developmental neuropsychology, 33(3), 205-228. https://doi.org/10.1080/87565640801982312

Blair, C., \& Raver, C. C. (2015). School readiness and self-regulation: A developmental psychobiological approach. Annual review of psychology, 66, 711-731. https://doi.org/10.1146/annurev-psych-010814-015221

Bledsoe, J. C., Semrud-Clikeman, M., \& Pliszka, S. R. (2010). Response inhibition and academic abilities in typically developing children with attention-deficit hyperactivity disorder-combined subtype. Archives of Clinical Neuropsychology, acq048. https://doi.org/10.1093/arclin/acq048

Brown, T. (2006). Executive functions and attention deficit hyperactivity disorder: Implications of two conflicting views. International Journal of Disability, 53, 35 46. https://doi.org/10.1080/10349120500510024

Catts, H. W., Compton, D., Tomblin, J. B., \& Bridges, M. S. (2012). Prevalence and nature of late-emerging poor readers. Journal of educational psychology, 104(1), 166.

Carlson, S. M., Zelazo, P. D., \& Faja, S. (2013). The Oxford Handbook of Developmental Psychology, Vol. 1: Body and Mind.

Cartwright, K.B. (2012). Insights from cognitive neuroscience: The importance of executive function for early reading development and education. Early Education and Development, 23, 24-36. https://doi.org/10.1080/10409289.2011.615025

Cartwright, K. B., Coppage, E. A., Lane, A. B., Singleton, T., Marshall, T. R., \& Bentivegna, C. (2016). Cognitive flexibility deficits in children with specific reading comprehension difficulties. Contemporary Educational Psychology. https://doi.org/10.1016/j.cedpsych.2016.01.003

Chan, R., Shum, D., Toulopoulou, T., \& Chen, E. (2008). Assessment of executive functions: Review of instruments and identification of critical issues. Archives of Clinical Neuropsychology, 23, 201-216. https://doi.org/10.1016/j.acn.2007.08.010

Chevignard, M. P., Servant, V., Mariller, A., Abada, G., Pradat-Diehl, P., \& LaurentVannier, A. (2009). Assessment of executive functioning in children after TBI with a naturalistic open-ended task: A pilot study. Developmental Neurorehabilitation, 12(2), 76-91. https://doi.org/10.1080/17518420902777019 
Chooi, W.-T., and Thompson, L.A. (2012) Working memory training does not improve intelligence in healthy young adults. Intelligence, 40: 531542.http://doi.org/10.1016/j.intell.2012.07.004

Christopher, M. E., Miyake, A., Keenan, J. M., Pennington, B., DeFries, J. C., Wadsworth, S. J., \& Olson, R. K. (2012). Predicting word reading and comprehension with executive function and speed measures across development: A latent variable analysis. Journal of Experimental Psychology: General, 141(3), 470. https://psycnet.apa.org/doi/10.1037/a0027375

Clark, C. A., Pritchard, V. E., \& Woodward, L. J. (2010). Preschool executive functioning abilities predict early mathematics achievement. Developmental psychology, 46(5), 1176. https://psycnet.apa.org/doi/10.1037/a0019672

Christopher, M. E., Miyake, A., Keenan, J. M., Pennington, B., DeFries, J. C., Wadsworth, S. J., ... \& Olson, R. K. (2012). Predicting word reading and comprehension with executive function and speed measures across development: a latent variable analysis. Journal of Experimental Psychology: General, 14l(3), 470. https://psycnet.apa.org/doi/10.1037/a0027375

Cohen, J., Cohen, P., West, S.G., \& Aiken, L.S. (2003). Applied multiple regression/ correlation analysis for the behavioral sciences. Mahwah, NJ: Erlbaum.

Coghill, D. R., Seth, S., \& Matthews, K. (2014). A comprehensive assessment of memory, delay aversion, timing, inhibition, decision making and variability in attention deficit hyperactivity disorder: advancing beyond the three-pathway models. Psychological medicine, 44(09), 1989-2001. https://doi.org/10.1017/S0033291713002547

Cortiella, C., \& Horowitz, S. H. (2014). The state of learning disabilities: Facts, trends and emerging issues. New York: National Center for Learning Disabilities.

Cutting, L. E., Materek, A., Cole, C. A., Levine, T. M., \& Mahone, E. M. (2009). Effects of fluency, oral language, and executive function on reading comprehension performance. Annals of dyslexia, 59(1), 34-54. https://doi.org/10.1177/002221949903200203

Dahlin, K. I. (2011). Effects of working memory training on reading in children with special needs. Reading and Writing, 24(4), 479-491. https://doi.org/10.1080/01443410.2013.797338

Denton, C. A. (2012). Response to intervention for reading difficulties in the primary grades some answers and lingering questions. Journal of Learning Disabilities, 45(3), 232-243. https://doi.org/10.1177\%2F0022219412442155 
Dexter, D. D., Park, Y. J., \& Hughes, C. A. (2011). A Meta-Analytic Review of Graphic Organizers and Science Instruction for Adolescents with Learning Disabilities: Implications for the Intermediate and Secondary Science Classroom. Learning Disabilities Research \& Practice, 26(4), 204-213. https://doi.org/10.1111/j.15405826.2011.00341.x

Espinet, S.D., Anderson, J.E., and Zelazo, P.D. (2013). Reflection training improves executive function in preschool children: Behavioral and neural effects. Developmental Cognitive Neuroscience, 4: 3-15. doi: 10.1016/j.den.2012.11.009

Ezpeleta, L., Granero, R., Penelo, E., de la Osa, N., \& Domènech, J. M. (2015). Behavior rating inventory of executive functioning-preschool (BRIEF-2-P) Applied to teachers psychometric properties and usefulness for disruptive disorders in 3year-old preschoolers. Journal of attention disorders, 19(6), 476-488. https://doi.org/10.1177\%2F1087054712466439

Fair, D. A., Bathula, D., Nikolas, M. A., \& Nigg, J. T. (2012). Distinct neuropsychological subgroups in typically developing youth inform heterogeneity in children with ADHD. Proceedings of the National Academy of Sciences, 109(17), 6769-6774. https://doi.org/10.1073/pnas.1115365109

Flanagan, D. P., Ortiz, S. O., Alfonso, V. C., \& Dynda, A. M. (2006). Integration of response to intervention and norm-referenced tests in learning disability identification: Learning from the Tower of Babel. Psychology in the Schools, 43(7), 807-825. https://doi.org/10.1002/pits.20190

Frye, R. E., Landry, S. H., Swank, P. R., \& Smith, K. E. (2009). Executive dysfunction in poor readers born prematurely at high risk. Developmental neuropsychology, 34(3), 254-271. https://doi.org/10.1080/87565640902805727

Fuchs, D., Fuchs, L. S., \& Stecker, P. M. (2010). The "blurring" of special education in a new continuum of general education placements and services. Exceptional Children, 76(3), 301-323. https://doi.org/10.1177\%2F001440291007600304

Fuchs, D., \& Fuchs, L. S. (2006). Introduction to response to intervention: What, why, and how valid is it?. Reading research quarterly, 41(1), 93-99. https://doi.org/10.1598/RRQ.41.1.4

Fuchs, D., Fuchs, L. S., \& Compton, D. L. (2012). Smart RTI: A next-generation approach to multilevel prevention. Exceptional children, 78(3), 263-279. https://doi.org/10.1177\%2F001440291207800301 
Fuchs, L. S., \& Vaughn, S. (2012). Responsiveness-to-intervention: A decade later. Journal of learning disabilities, 45(3), 195-203. https://doi.org/10.1177\%2F0022219412442150

Fuchs, L. S., Fuchs, D., Prentice, K., Burch, M., Hamlett, C. L., Owen, R., \& Schroeter, K. (2003). Enhancing third-grade student mathematical problem solving with self regulated learning strategies. Journal of educational psychology, 95(2), 306. https://psycnet.apa.org/doi/10.1037/0022-0663.95.2.306

García-Fernández, T., González-Castro, P., Fernández-Cueli, M., \& Rodríguez-Pérez, C. (2012). P-288-Conductual evaluation of executive functioning in attention deficit hyperactivity disorder and reading disabilities: utility of the BRIEF-2 scale (Gioia et al., 2000) adaptated into spanish. European Psychiatry, 27, 1. https://doi.org/10.1016/S0924-9338(12)74455-3

García-Madruga, J. A., Elosúa, M. R., Gil, L., Gómez-Veiga, I., Vila, J. Ó., Orjales, I., ... \& Duque, G. (2013). Reading comprehension and working memory's executive processes: An intervention study in primary school students. Reading Research Quarterly, 48(2), 155-174. https://doi.org/10.1002/rrq.44

Garon, N., Bryson, S. E., \& Smith, I. M. (2008). Executive function in preschoolers: a review using an integrative framework. Psychological bulletin, 134(1), 31. https://psycnet.apa.org/doi/10.1037/0033-2909.134.1.31

Geary, D. C. (2011). Cognitive predictors of achievement growth in mathematics: a 5year longitudinal study. Developmental psychology, 47(6), 1539. https://doi.org/10.1177\%2F1534508412451491

Gilbert, J. K., Compton, D. L., Fuchs, D., \& Fuchs, L. S. (2012). Early screening for risk of reading disabilities recommendations for a four-step screening system. Assessment for Effective Intervention, 38(1), 6-14. https://doi.org/10.1177\%2F1534508412451491

Gioia, G. A., Isquith, P. K., \& Guy, S. C. (2001). Assessment of executive functions in children with neurological impairment.

Goldstein, S., Naglieri, J. A., Princiotta, D., \& Otero, T. M. (2014). Introduction: a history of executive functioning as a theoretical and clinical construct. In Handbook of executive functioning (pp. 3-12). Springer New York.

Gioia, G.A., Espy, K.A., and Isquith, P.K. (2015). BRIEF-2: Behavior Rating Inventory of Executive Function: Professional Manual. Psychological Assessment Resources. 
Guajardo, N. R., \& Cartwright, K. B. (2016). The contribution of theory of mind, counterfactual reasoning, and executive function to pre-readers' language comprehension and later reading awareness and comprehension in elementary school. Journal of experimental child psychology, 144, 27-45. https://doi.org/10.1016/j.jecp.2015.11.004

Halloran, R. K. (2011). Self-Regulation, Executive Function, Working Memory, and Academic Achievement of Female High School Students. ProQuest LLC. 789 East Eisenhower Parkway, PO Box 1346, Ann Arbor, MI 48106.

Hassinger-Das, B., Jordan, N. C., Glutting, J., Irwin, C., \& Dyson, N. (2014). Domaingeneral mediators of the relation between kindergarten number sense and firstgrade mathematics achievement. Journal of experimental child psychology, 118, 78-92. https://doi.org/10.1016/j.jecp.2013.09.008

Horowitz, S. H., Rawe, J., \& Whittaker, M. C. (2017). The State of Learning Disabilities: Understanding the 1 in 5. New York: National Center for Learning Disabilities.

Hughes, C. (2011). Changes and challenges in 20 years of research into the development of executive functions. Infant and Child Development, 20(3), 251-271. https://doi.org/10.1002/icd.736

Individuals with Disabilities Education Improvement Act or 2004, p.L. 108-446

Isquith, P.K., Crawford, J.S., Espy, K.A., and Gioia, G.A. (2005). Assessment of executive function in preschool-aged children. Mental Retardation and Developmental Disabilities Research Reviews, 11: 209 - 215. https://doi.org/10.1002/mrdd.20075

Isquith, P. K., Roth, R. M., \& Gioia, G. (2013). Contribution of rating scales to the assessment of executive functions. Applied Neuropsychology: Child, 2(2), 125132. https://doi.org/10.1080/21622965.2013.748389

Jacob, R., \& Parkinson, J. (2015). The potential for school-based interventions that target executive function to improve academic achievement: A review. Review of Educational Research, 85(4), 512-552. https://doi.org/10.3102\%2F0034654314561338

Jacques, S., \& Marcovitch, S. (2010). Development of executive function across the life span. The handbook of life-span development.

Karbach, J., and Kray, J. (2009). How useful is executive control training? Age differences in near and far transfer of task-switching training. Developmental Science, 12(6): 978-990. https://doi.org/10.1111/j.1467-7687.2009.00846.x 
Kavale, K. A., \& Spaulding, L. S. (2008). Is response to intervention good policy for specific learning disability?. Learning Disabilities Research \& Practice, 23(4), 169-179. https://doi.org/10.1111/j.1540-5826.2008.00274.x

Kibby, M. Y., Marks, W., Morgan, S., \& Long, C. J. (2004). Specific impairment in developmental reading disabilities a working memory approach. Journal of learning disabilities, 37(4), 349-363. https://doi.org/10.1177\%2F00222194040370040601

Kieffer, M. J., Vukovic, R. K., \& Berry, D. (2013). Roles of attention shifting and inhibitory control in fourth-grade reading comprehension. Reading Research Quarterly, 48(4), 333-348. https://doi.org/10.1002/rrq.54

Kim, A. E., Oines, L., \& Miyake, A. (2018). Individual differences in verbal working memory underlie a tradeoff between semantic and structural processing difficulty during language comprehension: An ERP investigation. Journal of Experimental Psychology: Learning, Memory, and Cognition, 44(3), 406. https://psycnet.apa.org/doi/10.1037/xlm0000457

Koutsoftas, A. D., Harmon, M. T., \& Gray, S. (2009). The effect of Tier 2 intervention for phonemic awareness in a response-to-intervention model in low-income preschool classrooms. Language, Speech, and Hearing Services in Schools, 40(2), 116-130. https://doi.org/10.1044/0161-1461(2008/07-0101)

Kolligian Jr, J., \& Sternberg, R. J. (1987). Intelligence, information processing, and specific learning disabilities: A triarchic synthesis. Journal of Learning Disabilities, 20(1), 8-17. https://doi.org/10.1177\%2F002221948702000103

Lamberts, K. F., Evans, J. J., \& Spikman, J. M. (2010). A real-life, ecologically valid test of executive functioning: The executive secretarial task. Journal of Clinical and Experimental Neuropsychology, 32(1), 56-65. https://doi.org/10.1080/13803390902806550

Lee, K., Ng, E. L., \& Ng, S. F. (2009). The contributions of working memory and executive functioning to problem representation and solution generation in algebraic word problems. Journal of Educational Psychology, 101(2), 373. https://psycnet.apa.org/doi/10.1037/a0016095

Locascio, G., Mahone, E. M., Eason, S. H., \& Cutting, L. E. (2010). Executive dysfunction among children with reading comprehension deficits. Journal of learning disabilities, 43(5), 441-454. https://doi.org/10.1177\%2F0022219409355476 
Luria, A. R. (1973). The working brain, An introduction to neuropsychology. London, England: Basic Books.

Lyons, K. E., \& Zelazo, P. D. (2011). Monitoring, metacognition, and executive function: elucidating the role of self-reflection in the development of self regulation. Advances in child development and behavior, 40, 379-412. https://doi.org/10.1016/B978-0-12386491-8.00010-4

Mackey, A. P., Hill, S. S., Stone, S. I., \& Bunge, S. A. (2011). Differential effects of reasoning and speed training in children. Developmental science, 14(3), 582-590. https://doi.org/10.1111/j.1467-7687.2010.01005.x

Mather, N., \& Gregg, N. (2006). Specific learning disabilities: Clarifying, not eliminating, a construct.

Marzocchi, G. M., Oosterlaan, J., Zuddas, A., Cavolina, P., Geurts, H., Redigolo, D., \& Sergeant, J. A. (2008). Contrasting deficits on executive functions between ADHD and reading disabled children. Journal of Child Psychology and Psychiatry, 49(5), 543-552. https://doi.org/10.1111/j.1469-7610.2007.01859.x

McClelland, M. M., Cameron, C. E., Connor, C. M., Farris, C. L., Jewkes, A. M., \& Morrison, F. J. (2007). Links between behavioral regulation and preschoolers' literacy, vocabulary, and math skills. Developmental psychology, 43(4), 947. https://psycnet.apa.org/doi/10.1037/0012-1649.43.4.947

McCloskey, G., \& Perkins, L. A. (2012). Essentials of executive functions assessment (Vol. 68). John Wiley \& Sons.

Melekoglu, M. A. (2011). Impact of motivation to read on reading gains for struggling readers with and without learning disabilities. Learning Disability Quarterly, 34(4), 248-261. https://doi.org/10.1177\%2F0731948711421761

Menezes, A., Dias, N. M., Trevisan, B. T., Carreiro, L. R. R., \& Seabra, A. G. (2015). Intervention for executive functions in Attention Deficit and Hyperactivity Disorder. Arquivos de Neuro-psiquiatria, 73(3), 227-236. http://dx.doi.org/10.1590/0004-282X20140225

Meuwissen, A. S., \& Zelazo, P. D. (2014). Hot and cool executive function: Foundations for learning and healthy development. Zero to Three, 35(2), 18-23.

Miyake, A., Friedman, N. P., Emerson, M. J., Witzki, A. H., Howerter, A., \& Wager, T. D. (2000). The unity and diversity of executive functions and their contributions to complex "frontal lobe" tasks: A latent variable analysis. Cognitive psychology, 41(1), 49-100. https://doi.org/10.1006/cogp.1999.0734 
Moffitt, T. E., Arseneault, L., Belsky, D., Dickson, N., Hancox, R. J., Harrington, H., \& Sears, M. R. (2011). A gradient of childhood self-control predicts health, wealth, and public safety. Proceedings of the National Academy of Sciences, 108(7), 2693-2698. https://doi.org/10.1073/pnas.1010076108

Morrison, F. J., Ponitz, C. C., \& McClelland, M. M. (2010). Self-regulation and academic achievement in the transition to school. Child development at the intersection of emotion and cognition, 203-224.

Nation, K., Cocksey, J., Taylor, J. S., \& Bishop, D. V. (2010). A longitudinal investigation of early reading and language skills in children with poor reading comprehension. Journal of Child Psychology and Psychiatry, 51(9), 1031-1039. https://doi.org/10.1111/j.1469-7610.2010.02254.x

Nilsen, E. S., Huyder, V., McAuley, T., \& Liebermann, D. (2017). Ratings of everyday executive functioning (REEF): A parent-report measure of preschoolers' executive functioning skills. Psychological assessment, 29(1), 50. https://doi.org/10.1037/pas0000308

O'Connor, R. E., Bocian, K. M., Beach, K. D., Sanchez, V., \& Flynn, L. J. (2013). Special education in a 4-year response to intervention (RtI) environment: Characteristics of students with learning disability and grade of identification. Learning Disabilities Research \& Practice, 28(3), 98-112. https://doi.org/10.1111/ldrp.12013

Parke, E. M., Thaler, N. S., Etcoff, L. M., \& Allen, D. N. (2015). Intellectual profiles in children with ADHD and comorbid learning and motor disorders. Journal of attention disorders, 1087054715576343.

Pham, A. V., \& Hasson, R. M. (2014). Verbal and visuospatial working memory as predictors of children's reading ability. Archives of Clinical Neuropsychology, acu024.

Roth, R.M., Lance, C.E., Isquith, P.K., Fischer, A.S., and Giancola, P.R. (2013). Confirmatory factor analysis of the Behavior Rating Inventory of Executive Function-Adult Version in healthy adults and application to AttentionDeficit/Hyperactivity Disorder. Archives of Clinical Neuropsychology, 28(5): 425-434. https://doi.org/10.1076/chin.8.4.249.13513

Semrud-Clikeman, M., \& Harder, L. (2010). Neuropsychological correlates of written expression in college students with ADHD. Journal of Attention Disorders. 
Semrud-Clikeman, M., Pliszka, S., \& Liotti, M. (2008). Executive functioning in children with attention-deficit/hyperactivity disorder: Combined type with and without a stimulant medication history. Neuropsychology, 22(3), 329. https://psycnet.apa.org/doi/10.1037/0894-4105.22.3.329

Sesma, H. W., Mahone, E. M., Levine, T., Eason, S. H., \& Cutting, L. E. (2009). The contribution of executive skills to reading comprehension. Child Neuropsychology, 15(3), 232-246. https://doi.org/10.1080/09297040802220029

Siegler, R. S., \& Pyke, A. A. (2013). Developmental and individual differences in understanding of fractions. Developmental psychology, 49(10), 1994. https://psycnet.apa.org/doi/10.1037/a0031200

Spencer-Smith, M., and Klingberg, T. (2015). Benefits of a working memory training program for inattention in daily life: A systematic review and meta-analysis. PLoS ONE, 10(3):e0119522. doi: 10.1371/journal.pone.0119522

Spencer, M., Wagner, R. K., Schatschneider, C., Quinn, J. M., Lopez, D., \& Petscher, Y. (2014). Incorporating RTI in a hybrid model of reading disability. Learning Disability Quarterly, 37(3), 161-171. https://doi.org/10.1177\%2F0731948714530967

Strobach, T., Salminen, T., Karbach, J., \& Schubert, T. (2014). Practice-related optimization and transfer of executive functions: a general review and a specific realization of their mechanisms in dual tasks. Psychological research, 78(6), 836851. https://doi.org/10.1007/s00426-014-0563-7

Thompson, T.W., Waskom, M.L., Garel, K-LA, Cardenas-Iniguez, C., Reynolds, G,O., Winter, R., \& Gabrieli, J.D.E. (2013) Failure of working memory training to enhance cognition or intelligence. PLoS ONE 8(5): e63614. doi: 10.1371/journal.pone.006361

Toplak, M. E., West, R. F., \& Stanovich, K. E. (2013). Practitioner review: Do performance-based measures and ratings of executive function assess the same construct?. Journal of Child Psychology and Psychiatry, 54(2), 131-143. https://doi.org/10.1111/jcpp.12001

U.S. Department of Education Office for Civil Rights (2014). Civil rights data collection: Data snapshot (Early Childhood). Washington, DC: U.S. Department of Education.

Vukovic, R. K., Fuchs, L. S., Geary, D. C., Jordan, N. C., Gersten, R., \& Siegler, R. S. (2014). Sources of individual differences in children's understanding of fractions. Child Development, 85(4), 1461-1476. https://doi.org/10.1111/cdev.12218 
Welsh, J. A., Nix, R. L., Blair, C., Bierman, K. L., \& Nelson, K. E. (2010). The development of cognitive skills and gains in academic school readiness for children from low-income families. Journal of educational psychology, 102(1), 43. https://doi.org/10.1037/a0016738

Willcutt, E. G., Petrill, S. A., Wu, S., Boada, R., DeFries, J. C., Olson, R. K., \& Pennington, B. F. (2013). Comorbidity between reading disability and math disability concurrent psychopathology, functional impairment, and neuropsychological functioning. Journal of learning disabilities, 46(6), 500-516. https://doi.org/10.1177\%2F0022219413477476

Zelazo, P. D., Blair, C. B., Willoughby, M. T., Larson, M., Higgins, E., \& Sussman, A. (2016) Executive Function: Implications for Education.

Zelazo, P. D. (2015). Executive function: Reflection, iterative reprocessing, complexity, and the developing brain. Developmental Review, 38, 55-68. https://doi.org/10.1016/j.dr.2015.07.001

Zelazo, P. D., Craik, F. I., \& Booth, L. (2004). Executive function across the life span. Acta Psychological, 115(2), 167-183. https://doi.org/10.1080/09297049.2014.889110

Zelazo, P. D., \& Cunningham, W. A. (2007). Executive Function: Mechanisms Underlying Emotion Regulation.

Zelazo, P. D., \& Lyons, K. E. (2011). Mindfulness training in childhood. Human development, 54(2), 61-65. DOI:10.1159/000327548

Zimmerman, B. J. (2008). Investigating self-regulation and motivation: Historical background, methodological developments, and future prospects. American educational research journal, 45(1), 166-183. https://doi.org/10.3102\%2F0002831207312909 


\section{APPENDICIES}


APPENDIX A

BRIEF-2 QUESTIONAIRE 


\section{Executive Functioning Questionaire - BRIEF-2 Inhibition, Shift, and Working}

\begin{tabular}{|c|l|l|l|l|}
\hline $\begin{array}{c}\text { BRIEF } \\
\text { Item } \\
\text { Number }\end{array}$ & Question & \multicolumn{2}{|l|}{ Rating } \\
\hline 1 & Is Fidgity & Never & Sometimes & Often \\
\hline 2 & $\begin{array}{l}\text { Resists or has trouble accepting a different way to solve a } \\
\text { problem with schoolwork, friends, tasks, etc. }\end{array}$ & Never & Sometimes & Often \\
\hline 3 & $\begin{array}{l}\text { When given three things to do, remembers only the first or } \\
\text { last }\end{array}$ & Never & Sometimes & Often \\
\hline 10 & Does not think before doing (is impulsive) & Never & Sometimes & Often \\
\hline 11 & $\begin{array}{l}\text { fas trouble getting used to new situations (classes, groups, } \\
\text { friends, etc.) }\end{array}$ & Never & Sometimes & Often \\
\hline 12 & Has a short attention span & Never & Sometimes & Often \\
\hline 16 & Gets out of control more than friends & Never & Sometimes & Often \\
\hline 17 & Gets stuck on one topic or activity & Never & Sometimes & Often \\
\hline 19 & Has trouble with tasks that have more than one step & Never & Sometimes & Often \\
\hline 24 & Talks at the wrong time & Never & Sometimes & Often \\
\hline 25 & Has trouble finishing tasks (assignments, homework, etc.) & Never & Sometimes & Often \\
\hline 28 & Has trouble remembering things, even for a few minutes & Never & Sometimes & Often \\
\hline 30 & Gets out of seat at the wrong times & Never & Sometimes & Often \\
\hline 31 & Becomes upset with new situations & Never & Sometimes & Often \\
\hline 32 & Has trouble concentrating on schoolwork, etc. & Never & Sometimes & Often \\
\hline 39 & Acts too wild or "outofcontrol" & Never & Sometimes & Often \\
\hline 40 & Thinks too much about the same topic & Never & Sometimes & Often \\
\hline 41 & Forgets what he/she was doing & Never & Sometimes & Often \\
\hline
\end{tabular}

Doctoral Dissertation Study

\begin{tabular}{|c|l|c|c|c|}
\hline 46 & Needs help from an adult to stay on task & Never & Sometimes & Often \\
\hline 48 & Has trouble putting the brakes on his/her actions & Never & Sometimes & Often \\
\hline 49 & Resists change of routine, foods, places, etc. & Never & Sometimes & Often \\
\hline 58 & Does not think of consequences before acting & Never & Sometimes & Often \\
\hline 60 & $\begin{array}{l}\text { Has problems coming up with different ways of solving a } \\
\text { problem }\end{array}$ & Never & Sometimes & Often \\
\hline 63 & $\begin{array}{l}\text { Has trouble thinking of a different way to solve a problem } \\
\text { when stuck }\end{array}$ & Never & Sometimes & Often \\
\hline
\end{tabular}


APPENDIX B

CONSENT FORM 


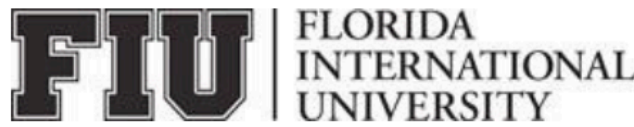

\author{
PARENTAL CONSENT TO PARTICIPATE IN A RESEARCH STUDY \\ A Comparison Study of the Executive Functioning Abilities and Reading Comprehension Skills of \\ Students in Response to Intervention
}

\section{PURPOSE OF THE STUDY}

You are being asked to give your permission for your child to be in a research study. The purpose of this study is to learn more about how your child's attention, memory, and mental shifting affect his or her reading comprehension skills.

\section{NUMBER OF STUDY PARTICIPANTS}

If you agree to allow your child to participate in this study, he/she will be one of 90 students in this research study.

\section{DURATION OF THE STUDY}

Your child's participation will require no direct participation from your child. His or her reading comprehension data (iReady scores) and attention, memory, and mental shifting (Executive Functioning Teacher questionnaire) will be analyzed.

\section{PROCEDURES}

If your child participates in this study, your child will not directly have to participate. In fact he or she does not need to know that they are participating in a study:

1. The researcher will access your child's winter iReady reading comprehensionassessment results.

2. The researcher will provide your child's teacher with a questionnaire that asks him or her to provide ratings on your child's attention, memory, and mental shifting abilities.

3. The researcher will analyze the data for your child to determine the relationships between his or her attention abilities, memory abilities, and mental shifting abilities and his or her reading comprehension skills.

\section{RISKS AND/OR DISCOMFORTS}

There are no risks associated with your child's participation in this study.

\section{BENEFITS}

The following benefits may be associated with your child's participation in this study: You and your child's teacher can learn more about his or her strengths and or weakness in attention, memory, and mental shifting. Also, this information can help better guide reading comprehension instruction and interventions.

\section{ALTERNATIVES}

There are no known alternatives available to your child other than not taking part in this study. However, any significant new findings developed during the course of the research which may relate to your child's willingness to continue participation will be provided to you.

\section{CONFIDENTIALITY}

The records of this study will be kept private and will be protected to the fullest extent provided by 
law. In any sort of report we might publish, we will not include any information that will make it possible to identify your child as a subject. Research records will be stored securely and only the researcher team will have access to the records. However, your child's records may be reviewed for audit purposes by authorized University or other agents who will be bound by the same provisions of confidentiality.

\section{COMPENSATION \& COSTS}

There is no compensation provided to the subject. Your child will not be responsible for any costs to participate in this study.

\section{RIGHT TO DECLINE OR WITHDRAW}

Your child's participation in this study is voluntary. Your child is free to participate in the study or withdraw his/her consent at any time during the study. Your child's withdrawal or lack of participation will not affect any benefits to which he/she is otherwise entitled. The investigator reserves the right to remove your child from the study without your consent at such time that they feel it is in the best interest.

\section{RESEARCHER CONTACT INFORMATION}

If you have any questions about the purpose, procedures, or any other issues relating to this research study you may contact Catherine S. Salum at FIU, 305-494-8463, Cschu003@fiu.edu.

\section{IRB CONTACT INFORMATION}

If you would like to talk with someone about your child's rights of being a subject in this research study or about ethical issues with this research study, you may contact the FIU Office of Research Integrity by phone at 305-348-2494 or by email at ori@fiu.edu.

\section{PARTICIPANT AGREEMENT}

I have read the information in this consent form and agree to allow my child to participate in this study. I have had a chance to ask any questions I have about this study, and they have been answered for me. I understand that I will be given a copy of this form for my records.

Signature of Parent/Guardian

Date

Printed Name of Parent/ Guardian

Printed Name of Child Participant

Signature of Person Obtaining Consent

Date 
VITA

\section{CATHERINE SCHULTHEIS SALUM}

2019

2010

2010

2004

Current

Current

Current

2014-2016
Ed.D. Exceptional Student Education

Florida International University

Miami, FL

P.D. School Psychology

Fordham University

New York, NY

MS.Ed. Educational Psychology

Fordham University

New York, NY

B.S. Early Childhood Education Florida International University Miami, FL

School Psychologist Licensure

Florida Department of Health

Florida Teaching Certificate

Tallahassee, FL

School Psychologist

Miami, FL

Graduate Assistant

Florida International University

\section{RESEARCH, PUBLICATIONS, AND PRESENTATIONS}

A Comparison Study of the Executive Functioning Abilities and the Reading Achievement of Students in Response to Intervention

DISSERTATION- Proposal defense 2017 -Dissertation defense Spring 2019

A Comparison Study of the Executive Functioning Abilities and the Reading Achievement of Students in Response to Intervention

PRESENTATION- NASP 2019 Conference

A Study of Teacher Perceptions on How Common Core Curriculum is Affecting Special Education

REVISIONS FROM PUBLISHERS - 2017 